\title{
Article \\ Preparation of High-Performance Metal-Free UV/Near Infrared-Shielding Films for Human Skin Protection
}

\author{
Chih-Hao Liang ${ }^{1}$ and Ying-Jung Chen $2,3,4, *,+(\mathbb{D}$ \\ 1 R\&D Division, Walsin Technology Corporation, Kaohsiung 806, Taiwan; liangchihhao1983@gmail.com \\ 2 Department of Fragrance and Cosmetic Science, Kaohsiung Medical University, Kaohsiung 807, Taiwan \\ 3 Drug Development and Value Creation Research Center, Kaohsiung Medical University, \\ Kaohsiung 807, Taiwan \\ 4 Department of Medical Research, Kaohsiung Medical University Hospital, Kaohsiung 807, Taiwan \\ * Correspondence: yjchen@kmu.edu.tw \\ + Current address: NO. 100, Shih-Chuan 1st Road, Kaohsiung 80708, Taiwan.
}

Citation: Liang, C.-H.; Chen, Y.-J. Preparation of High-Performance Metal-Free UV/Near

Infrared-Shielding Films for Human Skin Protection. Nanomaterials 2021, 11, 1954. https://doi.org/10.3390/ nano11081954

Academic Editor: Maria

Pilar Vinardell

Received: 20 June 2021

Accepted: 26 July 2021

Published: 29 July 2021

Publisher's Note: MDPI stays neutral with regard to jurisdictional claims in published maps and institutional affiliations.

Copyright: () 2021 by the authors. Licensee MDPI, Basel, Switzerland. This article is an open access article distributed under the terms and conditions of the Creative Commons Attribution (CC BY) license (https:// creativecommons.org/licenses/by/ $4.0 /)$.

\begin{abstract}
A series of metal-free UV/near infrared (NIR)-shielding coatings are successfully fabricated by shielded cathodic arc plasma evaporation (CAPE) and substrate-biased RF magnetron sputtering processes. The UV/NIR-shielding coatings comprising quarter-wave stacks of $\mathrm{TiO}_{2} / \mathrm{SiO}_{2}$ multilayers and high-conductivity sputter-deposited ITO films with a thickness in the range of 200-600 nm could block IRA and IRB radiations, respectively. The total thicknesses of UV/near infrared-shielding films are in the range from $375 \mathrm{~nm}$ to $1513.8 \mathrm{~nm}$. The anatase-phase $\mathrm{TiO}_{2}$ films with absorption edge located at $\sim 375 \mathrm{~nm}$ were deposited by shielded CAPE at $\sim 100{ }^{\circ} \mathrm{C}$. Further, the well-crystallized ITO films were found to have high free-electron concentrations $\left(1.12 \times 10^{21} \mathrm{~cm}^{-3}\right)$, resulting in strong absorption of IRB due to the plasmon resonance absorption. The optimal optical design and ITO film thickness were investigated, and the $\mathrm{TiO}_{2}\left(\mathrm{SiO}_{2} / \mathrm{TiO}_{2}\right)_{3}$ multilayer combined with an ITO film thickness of $400 \mathrm{~nm}$ was found to provide a high NIR-shielding rate of $94.8 \%$, UVB to UVAshielding rate of $92.7 \%$, and average visible light transmittance of $68.1 \%$. Further, human skin cells protected by a UV/NIR-shielding coating showed significantly decreased reactive oxygen species generation and inflammatory cytokine expression as compared to those of unprotected cells. The results demonstrate that the development of multifunction coatings have potential for transparent heat insulation windows and human skin protection against UV/IR radiations.
\end{abstract}

Keywords: heat insulation; UV absorption; $\mathrm{TiO}_{2} / \mathrm{SiO}_{2}$ multilayers; ITO; fibroblasts; human skin

\section{Introduction}

Solar radiation near the Earth's surface consists of a wide range of wavelengths, divided into three main ranges: UV, visible, and infrared (IR) radiations. While the IR light comprises $\sim 54 \%$ of the total amount of the solar energy, the UV light (including the three types: UVA, UVB, and UVC) accounts for only 7\% [1]. UVA (320-400 nm) can penetrate the epidermis layer to the dermis layer, leading to a photosensitive reaction via free radical generation [2]. Therefore, sunscreen materials are widely used in UVA (wavelength: $320-400 \mathrm{~nm}$ ) and UVB (wavelength: $280-320 \mathrm{~nm}$ ) protection for reducing the risk of skin cancers such as basal-cell carcinoma [3] and squamous-cell carcinoma [4]. Further, the conversion of the absorbed IR light into thermal causes an increase in the temperature of the window glass panes to a level as high as $50{ }^{\circ} \mathrm{C}$, resulting in heat radiation into indoor spaces [5]. Thus, a large amount of energy is consumed in ensuring thermal comfort inside buildings using devices such as air-conditioning systems. Moreover, recent studies have indicated that IR light, which is subdivided into IRA (wavelength: 760-1400 nm), IRB (wavelength: 1400-3000 $\mathrm{nm}$ ), and IRC ( $3000 \mathrm{~nm}$ to $1 \mathrm{~mm}$ ) ranges, can also cause skin damage and aging under prolonged sunlight exposure [6]. IRA radiation comprises a major portion of the IR wavelengths of the sunlight, and has a $65 \%$ skin-penetration rate, 
greater than those of the IRB, IRC, and UV wavelengths [7]. Therefore, there is a high demand for development of multifunction coatings, which are combined with saving the energy and human skin protection against both UV and NIR irradiations.

To protect against the adverse effects of UV light, titanium dioxide $\left(\mathrm{TiO}_{2}\right)$ powders are most widely used as sunscreen materials [8], because the band-to-band absorption edge of $\mathrm{TiO}_{2}$ in the anatase and rutile phases is located at $\sim 388 \mathrm{~nm}$ and $\sim 413 \mathrm{~nm}$, respectively (i.e., the band gap is $\sim 3.2$ and $\sim 3.0 \mathrm{eV}$ for the anatase and rutile phases of $\mathrm{TiO}_{2}$, respectively) [9]. Moreover, $\mathrm{TiO}_{2}$-based materials have also attracted significant attention for many other possible applications (e.g., as photocatalysts for the degradation of pollutants, self-cleaning and/or superhydrophilic surfaces [10], solar cell [11], and optical coatings [12]). The properties required for $\mathrm{TiO}_{2}$-based optical coatings are highly transparent and have a high refractive index in the visible light range [12]. Previous studies have extensively investigated the effects of the $\mathrm{TiO}_{2}$ microstructure on their photocatalytic activities and optical properties. These studies indicated that amorphous $\mathrm{TiO}_{2}$ has negligible photocatalytic activity, which was attributed to the recombination of the photoexcited holes and electrons at the trap sites [13]. In addition, amorphous $\mathrm{TiO}_{2}$ films have a lower bandgap $(\sim 2.4 \mathrm{eV})$, resulting in visible light absorption [14]. In general, a high growth temperature $\left(\sim 400{ }^{\circ} \mathrm{C}\right)$ is required for the transition of the amorphous $\mathrm{TiO}_{2}$ phase to the crystalline anatase phase [15]. In the case of $\mathrm{TiO}_{2}$ films deposited by the direct current (DC) sputter deposition process at room temperature, a high-temperature thermal treatment $\left(>300^{\circ} \mathrm{C}\right)$ is usually required to obtain well-crystallized anatase-phase films with a high reflective index and high visible light transmittance [16]. Previously, an ion-assisted deposition process was used to increase the refractive index of $\mathrm{TiO}_{2}$ films; it was achieved by the enhanced reactivity and high energy of the $\mathrm{Ti}$ ions impinging on the surface of $\mathrm{TiO}_{2}$ film during the deposition [12]. Among these ion-assisted deposition processes, cathodic arc plasma evaporation (CAPE) is the most promising method for growing highly crystalline films at a low substrate temperature, which is due to the high degree of ionization and suitable ion kinetic energies in the range of $10-100 \mathrm{eV}$ [12].

NIR-shielding coatings are designed to selectively reflect or absorb light in the NIR range and highly transmit in visible light range. For instance, thin metal coatings (such as $\mathrm{Ag}$ and $\mathrm{Au}$ thin film) have been applied on glass sheets for shielding the IR wavelengths, because they have high free electron densities, and hence have a the plasmon resonance absorption in the NIR region of $\sim 1000 \mathrm{~nm}$ [17]. Although Ag coatings have excellent NIR-shielding properties, they are chemically unstable and less durable in high-humidity environments. To improve the stability of Ag layers in high-humidity environments, metal oxide/metal/metal oxide (such as $\mathrm{MO}_{\mathrm{x}} / \mathrm{Ag} / \mathrm{MO}_{\mathrm{x}}$ ) multilayer coatings have been extensively explored as transparent energy-saving coatings [17,18]. However, Ag oxidation is a critical issue during the direct deposition of the oxide protection layer in an $\mathrm{O}_{2}$ reactive atmosphere on the Ag layer [19]. The Ag oxidation introduces large intrinsic stresses, leading to partial delamination of the film [20]; further, the visible light transmittance is also decreased due to considerable light absorption by the formed Ag oxides. The durability of the $\mathrm{MO}_{\mathrm{x}} / \mathrm{Ag} / \mathrm{MO}_{\mathrm{x}}$ multilayer coatings in humid environments depends on the internal stress of the $\mathrm{MO}_{\mathrm{x}}$ layers, and a higher internal stress renders the coatings less durable [21]. Moreover, studies on the thermal stability and oxidation resistance of $\mathrm{MO}_{\mathrm{x}} / \mathrm{Ag} / \mathrm{MO}_{\mathrm{x}}$ multilayer structures have indicated that oxygen out-diffuses into the Ag layer and oxidizes the thin Ag layer, leading to the formation of cracks in the multilayer structures [22]. In contrast, transparent conductive oxides (TCO) films are promising candidates for developing IR-shielding coatings, because they are chemically/thermally more stable than metal layers. Recently, TCO films and nanoparticles have been developed to serve as IR-shielding materials. The IR-reflecting edge (plasmon frequency) usually depends on the free electron density, because the IR absorption is due to the plasmon resonance. Therefore, intensive efforts have been devoted to improve the plasmon resonance absorption by increasing the free electron densities in these materials. The TCO materials have been tailored by adjusting their dopant concentration, as demonstrated for Zinc-oxide-based materials 
doped with group IIIA elements (Al, Ga) [23-25], PMMA-ITO composite coatings [26], and indium tin oxide (ITO) films [27]. However, the low IRA-shielding rate of these films remains an issue, because the plasmon resonance absorption of the TCOs lies in the NIR region of $>1400 \mathrm{~nm}$.

The aim of this work is to improve the chemical/thermal stability of UV/NIRshielding coatings. We developed a viable thin film deposition method for preparing metal-free transparent UV/NIR-shielding coatings. A multilayer structure of crystalline anatase-phase $\mathrm{TiO}_{2}$ and amorphous $\mathrm{SiO}_{2}$ is designed to reflect the IRA wavelengths, because these two materials are well-suited for this purpose owing to the large difference in their refractive indices and high visible light transparency. These oxide-based UV/NIRshielding coatings consists of $\mathrm{TiO}_{2}$ and $\mathrm{SiO}_{2}$ quarter-wave stack multilayers. The high UV-light-absorption $\mathrm{TiO}_{2}$ films were grown at a low temperature using the shielded CAPE technique. Further, ITO films with a high free carrier density, which exhibit high IRBshielding performance, were deposited by substrate-based radio frequency (RF) magnetron sputtering. These deposition techniques offer a low growth temperature to prevent the inter-diffusion between the multilayers. Thus, the novelty of this work is further improving chemical and thermal stability of UV/NIR-shielding coatings for human skin protection.

\section{Materials and Methods}

\subsection{Fabrication of the Samples}

IR-reflecting multilayer coatings of high-refractive-index $\mathrm{TiO}_{2}$ films and low-refractiveindex amorphous $\mathrm{SiO}_{2}$ films were deposited on glass substrates using steered CAPE with a shielded net and sputtering deposition, respectively. An arc cathode for the Ti source and an RF sputtering system for the Si source were installed on each side of the chamber wall. A rotatable substrate holder was located midway between the two sources. The distances from the arc cathode and sputter source to the substrate holder were 350 and $100 \mathrm{~mm}$, respectively. A circular Ti target (diameter: 4 inch) was fixed on the water-cooled circular arc source to improve thermal conduction. The steered arc process was used to prevent overheating, and thus decrease the emission of Ti microdroplets. Circular permanent magnets placed behind the circular cathode created a cycloidal path of the spot on the surface of the target. The magnetic field strength at the center of the cathode was $25 \mathrm{G}$, and it decreased gradually to $7 \mathrm{G}$ at the edge of the cathode. An electrically grounded shielded net (SUS304-made, 30 mesh) serving as the anode was located at a distance of $200 \mathrm{~mm}$ from the cathode surface between the cathode and substrate to prevent the Ti microdroplets from reaching the substrate. $\mathrm{TiO}_{2}$ films were deposited in an $\mathrm{O}_{2}$ gas atmosphere at a deposition pressure of $2.5 \mathrm{~Pa}$ and arc current of $80 \mathrm{~A}$. Before deposition, the chamber was evacuated to $<4.0 \times 10^{-4} \mathrm{~Pa}$. $\mathrm{SiO}_{2}$ films were grown by $\mathrm{RF}$ magnetron sputtering using a circular Si target (diameter: 3 inch) in an $\mathrm{Ar}-\mathrm{O}_{2}$ mixed gas atmosphere $\left(\mathrm{O}_{2} / \mathrm{Ar}=0.4\right)$ at a sputtering pressure of $0.53 \mathrm{~Pa}$ and RF sputtering power of $250 \mathrm{~W}$. Typical deposition rates were 1.2 and $1.3 \mathrm{~nm} / \mathrm{s}$ for the $\mathrm{TiO}_{2}$ and $\mathrm{SiO}_{2}$ films, respectively. The substrate temperature was maintained at $\sim 100{ }^{\circ} \mathrm{C}$ during the deposition and was monitored using a thermocouple. The thermocouple was fixed on the substrate hold to prevent the shift thermocouple position during loading/unloading samples and the distance between the tip of the thermocouple and the substrate was around $3 \mathrm{~mm}$. ITO films were subsequently deposited on the glass substrates on the opposite side of the $\mathrm{TiO}_{2} / \mathrm{SiO}_{2}$ multilayers by RF magnetron sputtering using a circular target (diameter: 3 inch) consisting of $90 \mathrm{wt} \% \operatorname{In}_{2} \mathrm{O}_{3}$ and $10 \mathrm{wt} \% \mathrm{SnO}_{2}$. The films were deposited in an Ar atmosphere at the sputtering pressure of $0.53 \mathrm{~Pa}$. An RF sputtering power of $150 \mathrm{~W}$ was used to generate the plasma. A bias voltage of $40 \mathrm{~V}$ was applied to the substrate using the RF power source. According to our previous studies, a negative bias of $40 \mathrm{~V}$ is a suitable condition for the ITO film growth, as it provides sufficient kinetic energy to enable the adatoms to reach the equilibrium position and for the relaxation of the residual stress. The substrate temperature was maintained at $\sim 150{ }^{\circ} \mathrm{C}$ during the sputtering process. ITO films with thicknesses of $200-600 \mathrm{~nm}$ were deposited at the rate of $\sim 1.5 \mathrm{~nm} / \mathrm{s}$. 


\subsection{Characterization of the Samples}

Film thicknesses were measured using a stylus surface profilometer (Tencor). An n\&k analyzer (model 1200, n\&k Technology, Santa Clara, CA, USA) was used to measure the refractive index $(n)$ of the $\mathrm{TiO}_{2}$ and amorphous $\mathrm{SiO}_{2}$ films in the wavelength range of $190-1000 \mathrm{~nm}$. The $n$ values were found to be 2.25 and 1.45 , respectively, for the $\mathrm{TiO}_{2}$ and $\mathrm{SiO}_{2}$ films. The optical transmission measurements were obtained using a UV-visible near-infrared spectrophotometer (200-2500 nm) (LAMBA 750, Perkin-Elmer, Inc., Spokane, WA, USA) in a double-beam configuration. The surface morphology of the coatings was observed using a scanning electron microscope (SEM, JSM-6330TF, JEOL, Tokyo, Japan). The cross-sectional microstructure of the coatings prepared by the focused ion beam (FIB) method were investigated using a field-emission transmission electron microscope (FETEM; Tecnai G2 F30, FEI, Hillsboro, OR, USA) at an accelerating voltage of $200 \mathrm{kV}$. Hall measurements were conducted for the electrical resistivity, carrier density, and mobility at room temperature in a Lake Shore system.

\subsection{Shielding Effects of UV/NIR Coatings on Human Skin Cells (Human Dermal Fibroblasts) 2.3.1. Cell Culture}

Human dermal fibroblasts were used to evaluate the UV/IR-induced skin damage. Human dermal fibroblasts (CCD-966SK cell line) obtained from the Bioresources Collection and Research Center (Hsinchu, Taiwan) were cultured in a minimum essential medium (Eagle) supplemented with $10 \%$ fetal calf serum, $0.1 \mathrm{mM}$ non-essential amino acids, $1.5 \mathrm{~g} / \mathrm{L}$ sodium bicarbonate, penicillin (100 units/mL)/streptomycin $(100 \mu \mathrm{g} / \mathrm{mL})$, and $1 \mathrm{mM}$ sodium pyruvate, and incubated at $37^{\circ} \mathrm{C}$ in an atmosphere of $95 \%$ air and $5 \% \mathrm{CO}_{2}$.

\subsubsection{UV/IR Irradiation}

The cells were washed with phosphate buffered saline (PBS) and then irradiated with the UVB light $\left(10 \mathrm{~mJ} / \mathrm{cm}^{2}\right)$ using UVP Crosslinker CL-3000 (AnalytikJena, Germany). For IR irradiation, PBS-covered cells were exposed to NIR radiation $\left(140 \mathrm{~J} / \mathrm{cm}^{2}\right)$ generated by a $175 \mathrm{~W}$ infrared lamp (IR175R PAR38, Philips, Amsterdam, The Netherlands). No increase in temperature was detected in PBS under these conditions. Control cells were held under similar conditions without irradiation. Following the treatment, the cells were incubated with the culture medium for desired durations at $37^{\circ} \mathrm{C}$.

\subsubsection{Evaluation of the Intracellular Reactive Oxygen Species (ROS) Production}

$\mathrm{H}_{2}$ DCFDA (2,7-dichlorodihydrofluorescein diacetate) was employed to detect the intracellular generation of ROS. The irradiated cells were collected and incubated with $10 \mu \mathrm{M}$ $\mathrm{H}_{2}$ DCFDA for 20 min prior to harvesting, and then washed with PBS. ROS generation was analyzed by flow cytometry (Beckman FC500, Beckman Coulter, CA, USA).

\subsubsection{Real-Time Polymerase Chain Reaction}

Total RNA was isolated from the non-irradiated control cells and UV-and/or IRirradiated cells using the RNeasy MiniKit (Geneaid Biotech Ltd., Taipei, Taiwan) according to the manufacturer. Reverse transcriptase reaction was performed with $2 \mu \mathrm{g}$ of total RNA using M-MLV reverse transcriptase (Promega, Madison, WI, USA) according to the manufacture's recommendation. Quantitative PCR was performed using ABI 7500 Real-Time PCR System (Applied Biosystems Inc., Foster City, CA, USA). PCR was performed using the GoTag qPCR Master Mix (Promega). The following thermocycling conditions were used: incubation at $95^{\circ} \mathrm{C}$ for $2 \mathrm{~min}$, followed by 40 cycles of amplification at $95^{\circ} \mathrm{C}$ for $15 \mathrm{~s}$, and then $60^{\circ} \mathrm{C}$ for $60 \mathrm{~s}$. The threshold cycle is defined as the cycle number at which the fluorescence corresponding to the amplified PCR product was detected. The PCR arbitrary units of each gene were defined as the mRNA levels normalized to the glyceraldehyde-3phosphate dehydrogenase (GAPDH) expression in each sample. The following primer sequences were used: GAPDH (forward primer) $5^{\prime}$-GAAATCCCATCACCATCTTCCAGG-3', GAPDH (reverse primer) 5'-GAGCCCCAGCCTTCTCCATG-3', TNF- $\alpha$ (forward primer) $5^{\prime}$ - 
AGCCCATGTTGTAGCAAACC-3', TNF- $\alpha$ (reverse primer) $5^{\prime}$-TGAGGTACAGGCCCTCTG AT-3', IL-6 (forward primer) 5'-CACAGACAGCCACTCACCTC-3', IL-6 (reverse primer) $5^{\prime}$-TTTTCTGCCAGTGCCTCTTT- $3^{\prime}$.

\section{Results and Discussion}

\subsection{Growth Mechanism and Microstructure of the $\mathrm{TiO}_{2}$ Film}

Figure 1 presents the X-ray diffraction (XRD) pattern of a $100 \mathrm{~nm}$ thick $\mathrm{TiO}_{2}$ film deposited on a glass substrate at $100{ }^{\circ} \mathrm{C}$ by CAPE using a shielded net (shielded CAPE) between the arc source and substrate. The diffraction peaks could be attributed to the antase-phase $\mathrm{TiO}_{2}$ (JCPDS card No. 21-1272) and the peaks could be indexed to the (101), (004), and (200) planes. Thus, the XRD analysis indicates that single-phase $\mathrm{TiO}_{2}$ films can be grown by this method, without any secondary phases. Although the $\mathrm{TiO}_{2}$ films were grown at a low temperature of $100{ }^{\circ} \mathrm{C}$, the intensive and sharp diffraction peaks indicated good crystallinity of the coatings. This is attributed to the ion-assisted growth arising from the high-ionization arc plasma [12]. In contrast, the formation of high-crystallinity $\mathrm{TiO}_{2}$ films through conventional vapor deposition without ion assistance generally requires a growth temperature of $>300{ }^{\circ} \mathrm{C}$ [15]. The XRD patterns exhibited a higher intensity of the (101) peak than other peaks, revealing the stronger tendency of the $\mathrm{TiO}_{2}$ crystallites to grow with a preferred (101) orientation. According to thermodynamics, a $\mathrm{TiO}_{2}$ structure with (101) orientation is more stable because of its lower surface free energy over that of a structure with (100) orientation [28]. Thus, the anatase-phase $\mathrm{TiO}_{2}$ films grew preferably along the [101] axis in the direction perpendicular to the glass substrate.

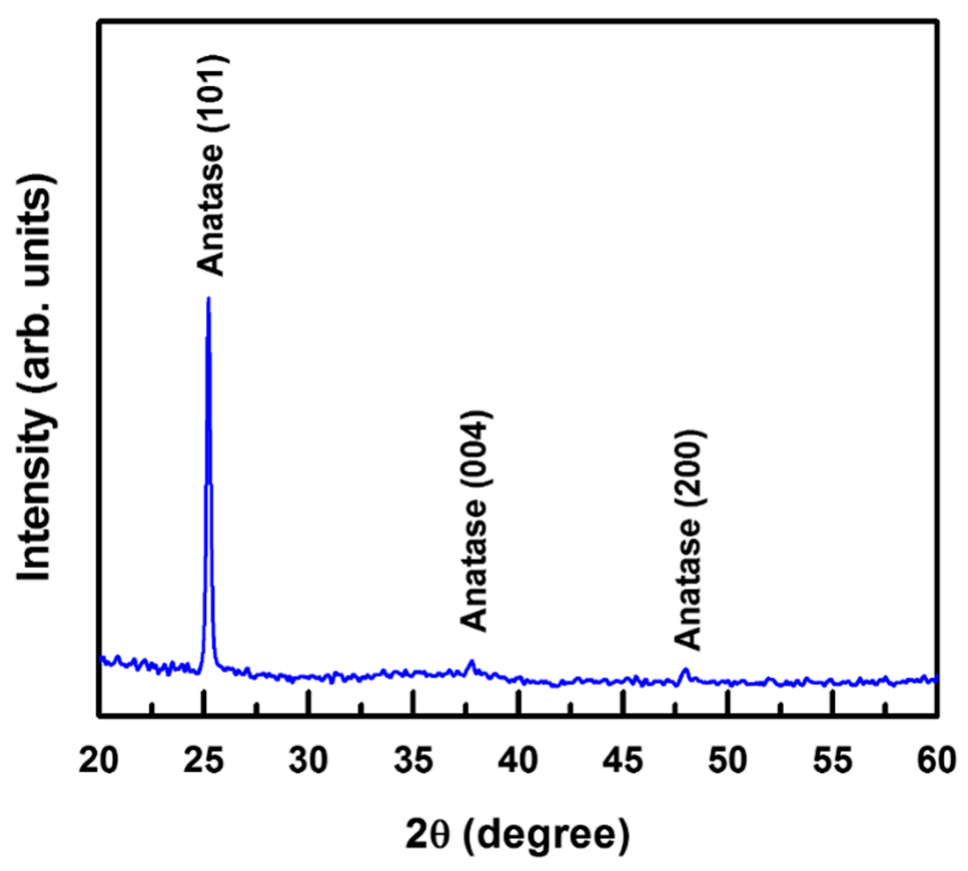

Figure 1. XRD pattern of a $100 \mathrm{~nm}$ thick $\mathrm{TiO}_{2}$ film deposited on a glass substrate at $100{ }^{\circ} \mathrm{C}$ by steered CAPE using a shielded net.

The variations in the surface morphology of the $\mathrm{TiO}_{2}$ thin films with the different deposition methods were examined by SEM to investigate the Ti microdroplet size distribution. Figure 2 shows the plane-view SEM images of the $\mathrm{TiO}_{2}$ thin films deposited by CAPE (a) without and (b) with a shielded net via the reaction of a Ti target with $\mathrm{O}_{2}$ at the temperature of $100^{\circ} \mathrm{C}$. Figure 2a shows some Ti microdroplets incorporated into the $\mathrm{TiO}_{2}$ film deposited by CAPE without a shielded net. The size of the microdroplets was in the range of 0.5 to $4 \mu \mathrm{m}$, as indicated by the arrows. As the cathode spots are a center of explosive electron emission on the target surface with an extremely high current 
density $\left(\sim 10^{12} \mathrm{~A} / \mathrm{m}^{2}\right)$, they create high ion kinetic energies (20-200 eV) and multiple charge states for ion-assisted growth [29]. However, the major disadvantage of this process is the emission of the microdroplets from the target, and their adhesion onto the films during their deposition. Large Ti microdroplets are emitted owing to the interaction between the arc plasma and Ti target at the cathode spots. In general, large microdroplets of sizes ranging up to several micrometers may cause a self-shadowing effect during the thin film growth process, leading to voids or gaps at the film-droplet interfaces [30]. The deposition of large microdroplets on a growing film results in degraded optical properties of the final film, owing to the opacity of the metal microdroplets and self-shadowing effect. These factors restrict the application of the CAPE process in the preparation of optical coatings. To overcome this issue of the incorporation of opaque metal microdroplets into the films, $\mathrm{TiO}_{2}$ films are prepared by shielded CAPE via the reaction of a Ti metal target with $\mathrm{O}_{2}$. The SEM image of the $\mathrm{TiO}_{2}$ film deposited by shielded CAPE (Figure $2 b$ ) exhibits only a few Ti nanodroplets incorporated in the film, and the size of the droplets is significantly decreased from several micrometers to $50-150 \mathrm{~nm}$, as marked by the arrows in the image. This result indicates that the liquid droplets of Ti emitted from the target were effectively blocked by the shielded net. However, the average growth rate decreased significantly from 8.5 to $1.2 \mathrm{~nm} / \mathrm{s}$ when the shielded CAPE method was used.
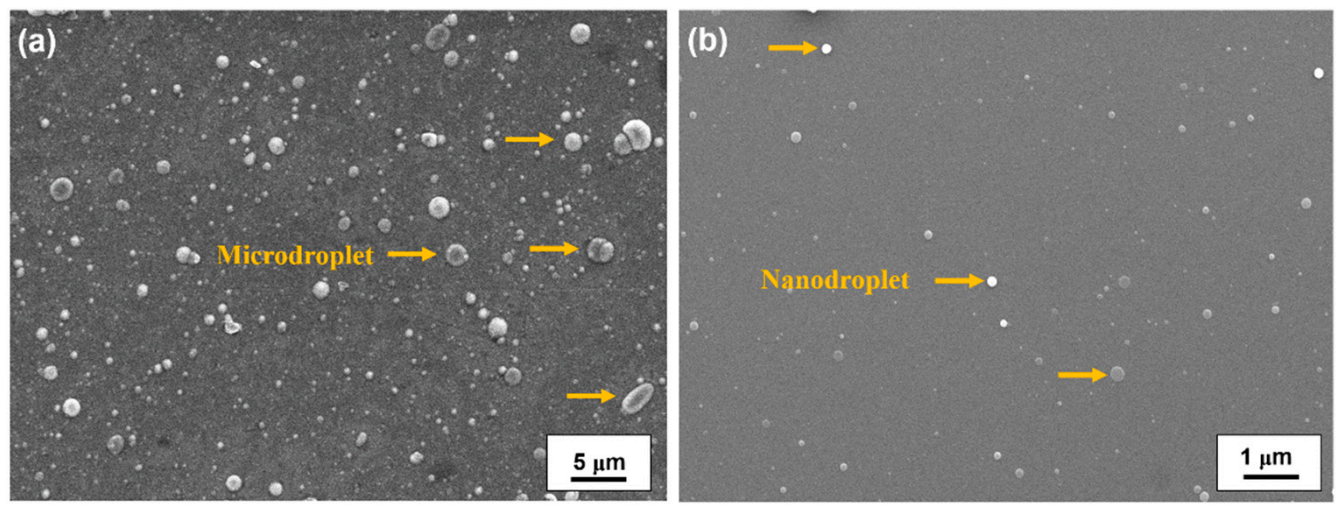

Figure 2. SEM images of $\mathrm{TiO}_{2}$ thin films deposited by CAPE: (a) without and (b) with a shielded net (shielded CAPE) through the reaction of a Ti target with $\mathrm{O}_{2}$ at the deposition temperature of $100{ }^{\circ} \mathrm{C}$.

Figure 3 displays the transmittance spectrum of a $\mathrm{TiO}_{2}$ thin film deposited by shielded $\mathrm{CAPE}$ via the reaction of a Ti target with $\mathrm{O}_{2}$ at the growth temperature of $100{ }^{\circ} \mathrm{C}$. The inset shows the optical band gap of the $\mathrm{TiO}_{2}$ coating. The series of broad peaks located at 391,497 , and $675 \mathrm{~nm}$ is due to light interference owing to the difference in the refractive index between the $\mathrm{TiO}_{2}$ thin film and glass substrate; it indicates the uniformity of the $\mathrm{TiO}_{2}$ film thickness. The transmittance spectrum indicates that the $\mathrm{TiO}_{2}$ films had an average transmittance $>83.6 \%$ in the visible light range $(400-760 \mathrm{~nm})$. The as-deposited $\mathrm{TiO}_{2}$ films obtained by shielded CAPE showed good visible light transmittance because the arc plasma provided sufficient energy to $\mathrm{Ti}$ and $\mathrm{O}$ adatoms to reach their equilibrium positions; thus, the undesired absorption due to structural defects is reduced. In contrast, $\mathrm{TiO}_{2}$ films deposited by the DC-sputtering deposition process require a higher thermal treatment temperature of $>300^{\circ} \mathrm{C}$ to enhance visible light transmittance, because high-temperature thermal annealing is required to eliminate the defects in the film [16].

To investigate the UV-shielding properties of the $\mathrm{TiO}_{2}$ films deposited by shielded CAPE, the indirect band gap of the $\mathrm{TiO}_{2}\left(\mathrm{E}_{g, \mathrm{TiO} 2}\right)$ film was determined from the absorption spectra using the indirect transition model [31]:

$$
(\alpha \mathrm{h} v)^{1 / 2}=A_{i}\left(\mathrm{~h} v-\mathrm{E}_{g, \mathrm{TiO} 2}\right)
$$

where $\alpha$ is the absorption coefficient, $A_{i}$ is a constant, and $\mathrm{h} v$ is the photon energy. The inset of Figure 3 shows the plot of $(\alpha \mathrm{h} v)^{1 / 2}$ versus the photon energy for the $\mathrm{TiO}_{2}$ film. 
According to Equation (1), the optical bandgap can be determined by extrapolating the linear region of the plot to the abscissa. The bandgap of the $\mathrm{TiO}_{2}$ films was thus determined to be $\sim 3.3 \mathrm{eV}$, which corresponds to the band-to-band transition of anatase-phase $\mathrm{TiO}_{2}$. This band-to-band transition (absorption edge at $\sim 375 \mathrm{~nm}$ ) facilitates a strong absorption in the UV range, leading to high UVB- and UVA-shielding properties.

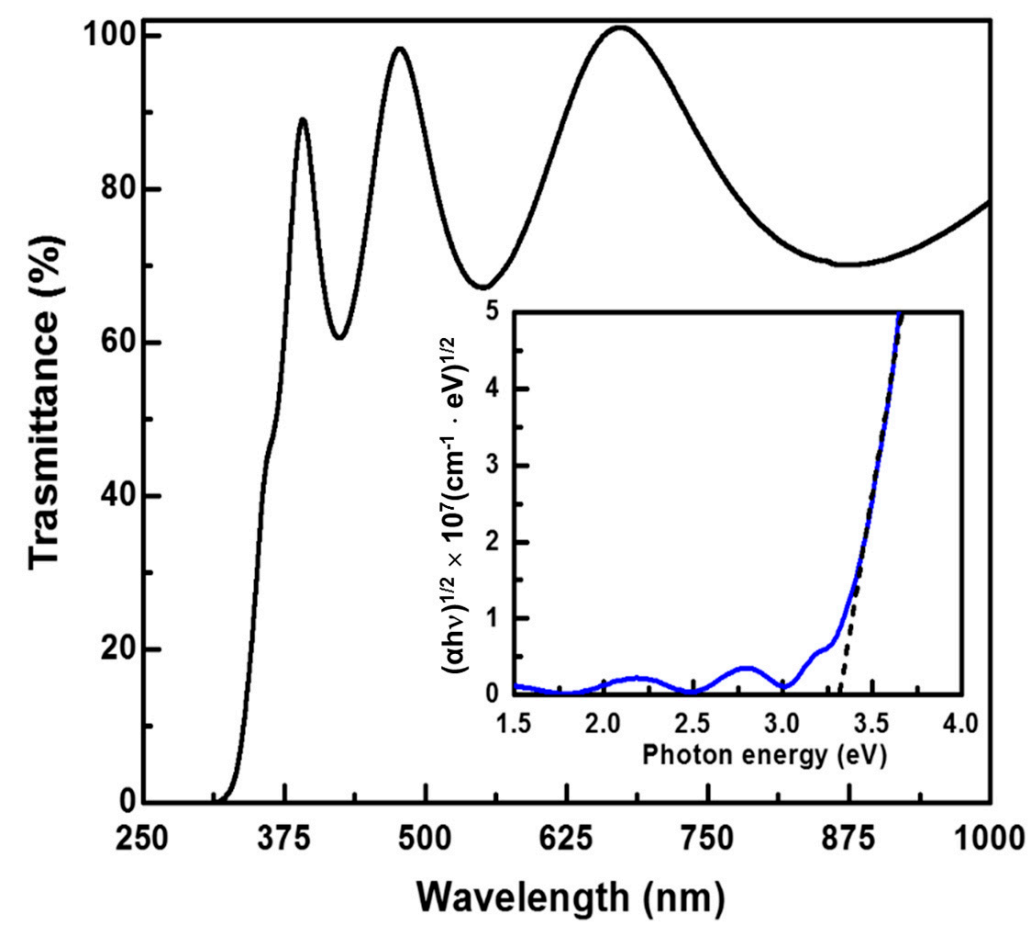

Figure 3. Transmittance spectrum of the $\mathrm{TiO}_{2}$ thin film deposited by steered CAPE with a shielded net (shielded CAPE) through the reaction of a Ti target with $\mathrm{O}_{2}$ at the deposition temperature of $100{ }^{\circ} \mathrm{C}$. Inset shows the plot of $(\alpha \mathrm{h} v)^{1 / 2}$ versus photon energy for the $\mathrm{TiO}_{2}$ thin film.

\subsection{IRB-Shielding ITO Layers}

ITO films have high visible light transparency and good IRB absorption properties owing to the plasmon excitation of the free electrons [27]. ITO films with a high free carrier concentration are prepared carefully to obtain a higher IRB-shielding rate. RF magnetron sputtering combined with a negatively biased substrate can facilitate intense ion bombardment during the film deposition. A suitable bias voltage can provide sufficient kinetic energy to enable the adatoms to reach the equilibrium position, resulting in a highly crystalline film. Therefore, ITO films were deposited on a glass substrate with an RF bias voltage of $-40 \mathrm{~V}$ at $150{ }^{\circ} \mathrm{C}$.

Figure 4 shows the XRD patterns of the ITO films with various thicknesses in the range of 200 to $600 \mathrm{~nm}$. All the recorded diffraction peaks could be indexed to the bixbyite structure of ITO (JCPDS card No. 89-4598). Thus, the XRD analysis indicated that the films were formed in the pure ITO phase, without any secondary phases. Despite the relatively low deposition temperature, the sharp diffraction peaks indicate a good crystallinity of the ITO coatings. This is attributed to enhanced ion bombardment resulting from the effect of the substrate bias. In general, the temperature required for the crystallization of amorphous ITO films is $\sim 300{ }^{\circ} \mathrm{C}$ [32]. The ion bombardment provided the adatoms with sufficient energy to move on the growing film surface. Thus, high-crystallinity ITO films could be deposited at a relatively low growth temperature of $150{ }^{\circ} \mathrm{C}$. Furthermore, the intensity ratio of the (400) and (222) diffraction peaks $\left(I_{400} / I_{222}\right)$ in the XRD patterns increased from 0.32 to 1.03 with an increase in the ITO film thickness from 200 to $600 \mathrm{~nm}$. The $I_{400} / I_{222}$ ratio of the $200 \mathrm{~nm}$ thick ITO film was determined to be 0.32 , comparable to that of a randomly oriented polycrystalline ITO powder $\left(I_{400} / I_{222}=0.30\right)$ [27]. The orientation of the initially 
formed ITO layer was influenced by the amorphous structure of glass substrate; therefore, a random orientation was observed when the film thickness was $200 \mathrm{~nm}$. The $I_{400} / I_{222}$ ratio increases significantly from 0.68 to 1.03 as the thickness was increased from 400 to $600 \mathrm{~nm}$, indicating that the (100) preferred orientation evolved with increasing film thickness.

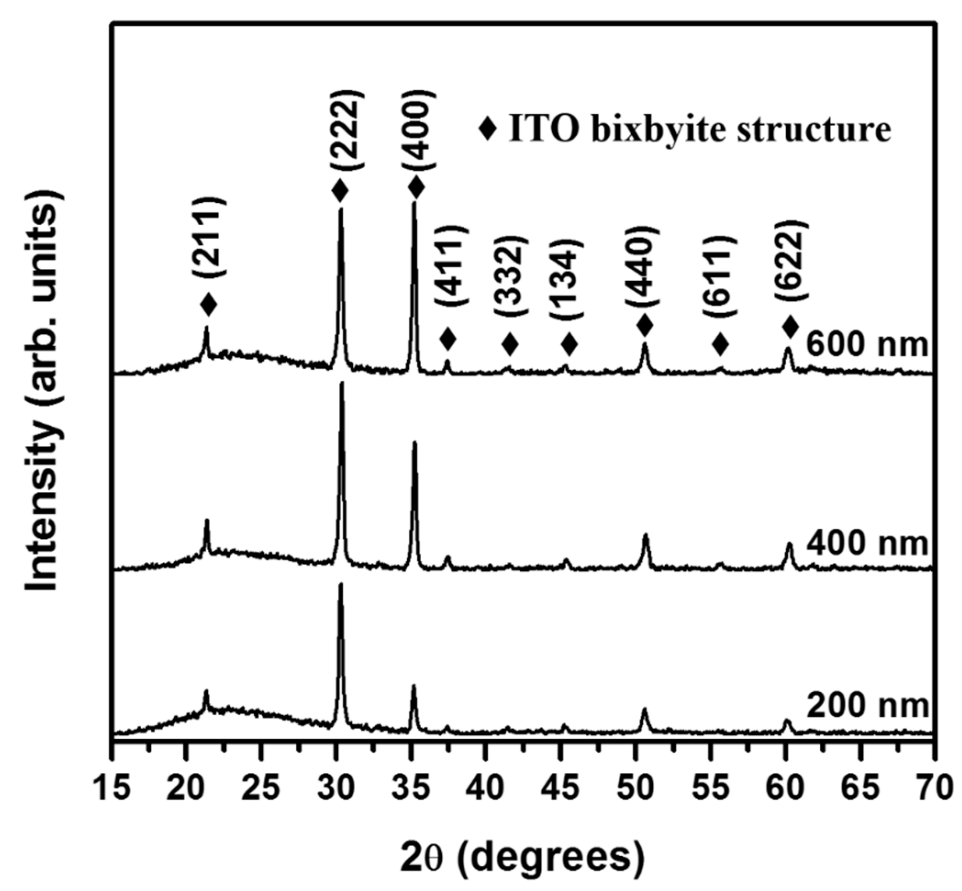

Figure 4. XRD patterns of the ITO thin films, with different thicknesses in the range of $200 \mathrm{~nm}$ to $600 \mathrm{~nm}$, deposited by substrate-biased RF magnetron sputtering. The ratio of the (400) to (222) diffraction peak intensity $\left(I_{400} / I_{222}\right)$ was calculated to be $0.323,0.678$, and 1.03 for the 200,400 , and $600 \mathrm{~nm}$ thick ITO films, respectively.

To further investigate the microstructure of the ITO films deposited by RF sputtering combined with a negatively biased $(-40 \mathrm{~V})$ substrate, a representative cross-sectional sample of a $400 \mathrm{~nm}$ thick film was analyzed by TEM (Figure 5). The cross-sectional brightfield (BF) TEM images revealed that the dense columnar structure of ITO film, as shown in Figure 5a. In addition, the initial growth region near the amorphous glass substrate contained small columnar grains $(\sim 40 \mathrm{~nm})$ and the columnar grains gradually coalesced into larger columnar grains ( $90 \mathrm{~nm})$ with an increase in the film ITO thickness to $400 \mathrm{~nm}$. Figure $5 b$,c show the nano-beam diffraction (NBD) patterns for the regions marked as NBD-I and NBD-II, respectively, in Figure 5a. The NBD patterns in Figure 5b,c were recorded along the [001] and [110] zone axes, respectively. The NBD could be indexed to the bixbyite-phase ITO with a lattice parameter of $1.016 \mathrm{~nm}$ [33]. According to the NBD analysis, the columnar ITO grains grow along the [100] direction, perpendicular to the plane of the substrate. Thus, the BF image and NBD patterns indicates that a (100)textured microstructure had formed in the ITO films at thicknesses greater than $400 \mathrm{~nm}$, consistent with the XRD results. According to Choi et al., ITO films that contain more oxygen vacancies provide sites for ions to migrate under the low oxygen sputtering growth condition [34]. In addition, the oxygen vacancies are preferentially incorporated into (100) planes than into (111) planes, because the former can accommodate more oxygen vacancies than the latter [33,34]. A large number of oxygen vacancy sites could assist ion diffusion owing to the open lattice structure of these sites. From the perspective of kinetics, only grains with the highest growth-rate lattice plane eventually survive [35]; therefore, the preferred (100) orientation was obtained at a greater film thickness. 

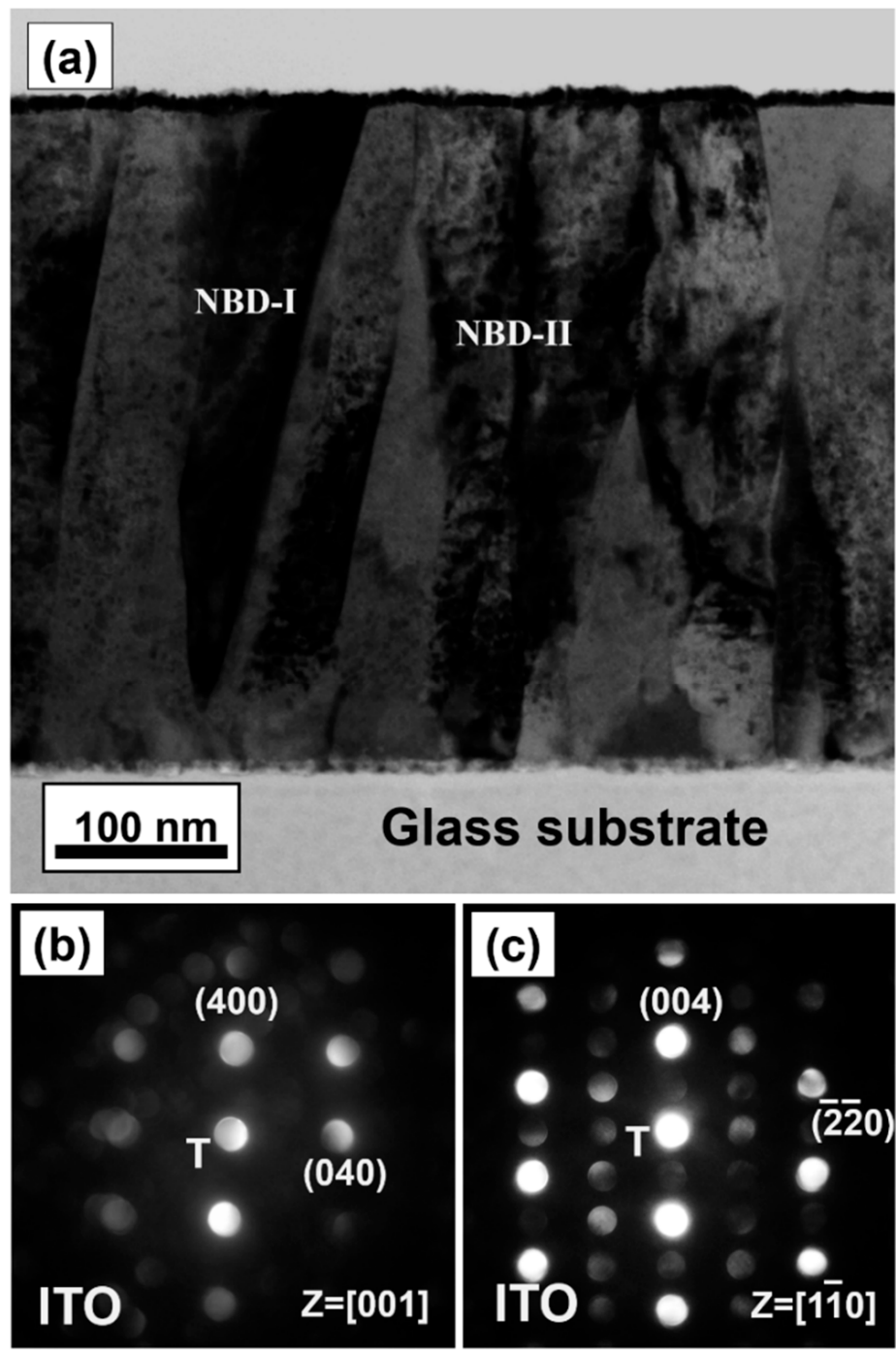

Figure 5. (a) A cross-sectional bright-field image transmission electron microscopy (TEM) image of the ITO film deposited on the glass substrate: $(\mathbf{b}, \mathbf{c})$ show the corresponding nano-beam diffraction patterns of regions marked as NBD-I and NBD-II in (a), respectively.

Figure 6a shows the transmittance spectra of the ITO coatings grown to different thicknesses (200 to $600 \mathrm{~nm}$ ). The optical properties, including the average transmittance from UVB to UVA ( $\left.T_{U V B} \sim U V A\right)$, average visible light transmittance $\left(T_{V I S}\right)$, average IRA transmittance $\left(T_{I R A}\right)$, and average IRB transmittance $\left(T_{I R B}\right)$ were calculated from the transmittance spectra. The electrical and optical properties, including the carrier density, Hall mobility, and resistivity, and the $T_{U V B} \sim U V A, T_{V I S}, T_{I R A}$, and $T_{I R B}$ values of the ITO films with different thicknesses $(200-600 \mathrm{~nm})$ are summarized in Table 1 . As the film thickness increased from 200 to $600 \mathrm{~nm}$, the Hall mobility increased from 25.9 to $31.8 \mathrm{~cm}^{2} / \mathrm{V} \mathrm{s}$. The carrier density also increased with the film thickness from $9.1 \times 10^{20}$ to $1.12 \times 10^{21} \mathrm{~cm}^{-3}$. Thus, the best conductivity was obtained at the thickness of $600 \mathrm{~nm}$. The changes in the electrical properties can be rationalized based on the microstructure, crystalline defects and effective donor density. The electrons encountered fewer scattering events during their transport, leading to higher mobility. The mobility increased continuously with an increase in the film thickness from 200 to $600 \mathrm{~nm}$, owing to the decrease in the number of scattering centers due to the reduction in the crystalline defects with increasing crystallite size. The crystallite size and crystallinity of the ITO films increase with an increase in the film thickness from 200 to $600 \mathrm{~nm}$, resulting in the increase in mobility with increasing film thickness. 

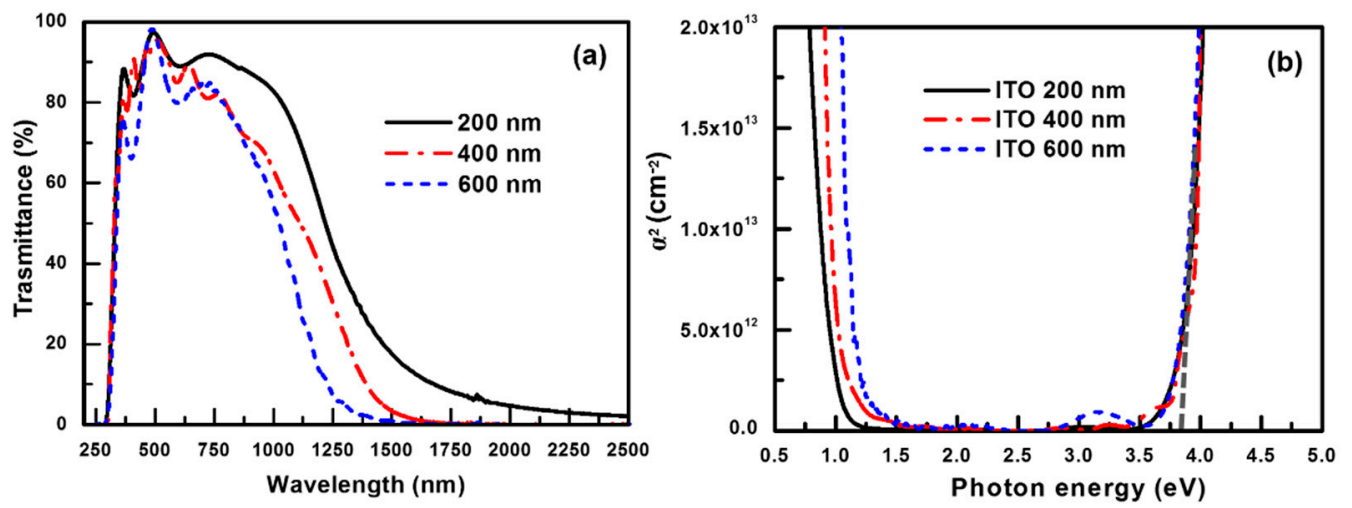

Figure 6. (a) Transmittance spectra and (b) absorption spectra of ITO films of different thicknesses in the range of 200 to $600 \mathrm{~nm}$.

Table 1. Carrier density, Hall mobility, resistivity, average transmittance in the UVB to UVA range ( $\left.T_{U V B} \sim U V A\right)$, average visible light transmittance $\left(T_{V I S}\right)$, average IRA light transmittance $\left(T_{I R A}\right)$, and average IRB light transmittance $\left(T_{I R B}\right)$ of ITO films with different thicknesses (200-600 nm).

\begin{tabular}{cccccccc}
\hline $\begin{array}{c}\text { ITO } \\
\text { Thickness } \\
(\mathbf{n m})\end{array}$ & $\begin{array}{c}\text { Carrier } \\
\text { Density } \\
\left(\times \mathbf{1 0}^{\mathbf{2 0}} / \mathbf{C m}^{\mathbf{3}}\right)\end{array}$ & $\begin{array}{c}\text { Hall } \\
\text { Mobility } \\
\left(\mathbf{c m}^{\mathbf{2}} / \mathbf{V} \cdot \mathbf{S e c}\right)\end{array}$ & $\begin{array}{c}\text { Resistivity } \\
\left(\times \mathbf{1 0}^{-4}\right)\end{array}$ & $\begin{array}{c}\mathbf{T}_{U V B \sim U V A} \\
\mathbf{( \% )}\end{array}$ & $\begin{array}{c}\mathbf{T}_{\text {VIS }} \\
\mathbf{( \% )}\end{array}$ & $\begin{array}{c}\mathbf{T}_{\text {IRA }} \\
\mathbf{( \% )}\end{array}$ & $\begin{array}{c}\boldsymbol{T}_{\text {IRB }} \\
\mathbf{( \% )}\end{array}$ \\
\hline 200 & 9.1 & 25.9 & 2.65 & 52.9 & 90.9 & 66.7 & 7.3 \\
400 & 10.5 & 30.4 & 1.96 & 50.9 & 87.5 & 50.3 & 0.9 \\
600 & 11.2 & 31.8 & 1.75 & 42.1 & 85.2 & 38.2 & 0.2 \\
\hline
\end{tabular}

The high carrier concentration of the high-crystallinity ITO film indicated that the $\mathrm{In}^{3+}$ ions were replaced by a $\mathrm{Sn}^{4+}$ donors, resulting in the donation of free electrons. Further, the incorporated oxygen vacancies can behave as double donors and the trapped electrons are easily thermally activated to the conduction band [33]. In contrast, grain boundaries and lattice distortion lead to large recombination centers owing to localized states related to the nearby dangling bonds, which could act as undesirable electron-trapping state [36,37]. The carrier concentration increases from $9.1 \times 10^{20}$ to $1.1 \times 10^{21} \mathrm{~cm}^{-3}$ with increasing thickness from $200 \mathrm{~nm}$ to $600 \mathrm{~nm}$. The film with $600 \mathrm{~nm}$ thickness has the highest election density, which originates from the increase in the effective dopant concentration due to the improved crystallinity and the decrease in the number of trapping sites arising from crystalline defects. In addition, the ITO films with the preferred (100) orientation at the thickness of $>400 \mathrm{~nm}$ can incorporate a higher number of oxygen vacancies, leading to higher carrier density.

Figure $6 \mathrm{~b}$ shows the square of the absorption coefficient versus the photon energy for ITO films of different film thicknesses. The bandgaps of the ITO films can be obtained based on the Moss method [38]. The optical bandgap of the ITO films ( $\left.\mathrm{E}_{g, \text { ITO }}\right)$ can be determined from the absorption coefficient of the films using the relationship for parabolic direct bands [27]:

$$
\alpha=\mathrm{A}\left(\mathrm{h} v-\mathrm{E}_{g, \mathrm{ITO}}\right)^{1 / 2}
$$

where $\alpha$ is absorption coefficient, $\mathrm{A}$ is a constant, and $\mathrm{h} v$ is the photon energy. According to Equation (2), the interpolation of the linear part of the $\alpha^{2}$ versus $h v$ plot onto the $h$ axis

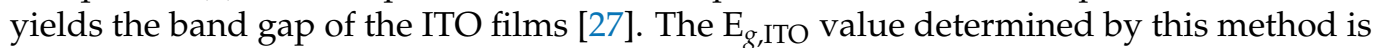
$\sim 3.75 \mathrm{eV}$ (absorption edge is located at $\sim 330 \mathrm{~nm}$ ); thus, ITO films cannot completely block the UVA radiation (wavelength: $320-400 \mathrm{~nm}$ ). Therefore, the $T_{U V B} \sim U V A$ value decreased only marginally from 52.9 to $48.1 \%$ owing to the band-to-band absorption of ITO. Moreover, ITO films have a high transmittance of $>85 \%$ in the visible light range; however, the $T_{V I S}$ value decreased slightly from 90.9 to $85.2 \%$ with increasing film thickness, as shown in Table 2. The visible light transmittance decreased with increasing ITO thickness owing 
to the broad absorption range of the ITO film, which may be attributed to the $\mathrm{s}^{2} \rightarrow \mathrm{sp}$ bonding transition of $\mathrm{Sn}^{2+}$ [33]. It has been suggested that the formation mechanism of $\mathrm{Sn}^{2+}$ ions involves the charge neutralization; therefore, $\mathrm{Sn}^{2+}$ ion were formed to the compensation of the local positive charge at $\mathrm{Sn}^{4+}$ in ITO films [33].

Table 2. Average visible light transmittance $\left(T_{V I S}\right)$, average IRA light transmittance $\left(T_{I R A}\right)$, and average IRB light transmittance $\left(T_{I R B}\right)$ of different optical designs, (I), (II), and (III). The multilayers consist of stacks of (I) $\mathrm{TiO}_{2}\left(\mathrm{SiO}_{2} / \mathrm{TiO}_{2}\right)$, (II) $\mathrm{TiO}_{2}\left(\mathrm{SiO}_{2} / \mathrm{TiO}_{2}\right)_{2}$, and (III) $\mathrm{TiO}_{2}\left(\mathrm{SiO}_{2} / \mathrm{TiO}_{2}\right)$ layers with a Bragg wavelength of $950 \mathrm{~nm}$.

\begin{tabular}{cccc}
\hline Optical Design & $\boldsymbol{T}_{\text {VIS }}(\mathbf{\%})$ & $\boldsymbol{T}_{\text {IRA }} \mathbf{( \% )}$ & $\boldsymbol{T}_{\boldsymbol{I R B}} \mathbf{( \% )}$ \\
\hline I & 81.6 & 45.1 & 93.5 \\
II & 77.8 & 38.5 & 89.3 \\
III & 72.7 & 38.2 & 88.8 \\
\hline
\end{tabular}

Further, the transmittance edge in the NIR region decreased from 1500 to $1250 \mathrm{~nm}$ with increasing thickness of the ITO film. The TIRA value decreased rapidly from 66.7 to $38.2 \%$, and the IRB radiation was effectively blocked (i.e., $T_{I R B}<1 \%$ ) at the ITO thickness of $>400 \mathrm{~nm}$, as shown in Table 1 . The transmittance in the IRB region decreased rapidly, because the plasmon resonance absorption was enhanced by the increased free electron density of the TCO film $[24,25]$. The plasmon resonance frequency $\left(\omega_{p}\right)$ is given by $\omega_{p}=\left(4 \pi \mathrm{Ne}^{2} / \varepsilon_{0} m^{*}\right)^{1 / 2}$, where $N$ is the density of free electrons, $e$ is the elementary charge, $\varepsilon_{0}$ is the permittivity of free space, and $m^{*}$ is the electron effective mass [24,25]. According to the Drude model, the absorption spectrum of plasmons can be described as follows [39]:

$$
\alpha=2 \omega / c\left(\omega_{p}^{2} / \omega^{2}-1\right)^{1 / 2}
$$

where $\alpha$ is the absorption coefficient and $\omega$ is frequency. The absorption coefficient decreases with increasing frequency and it becomes zero for $\omega>\omega_{p}$. The carrier concentration of the ITO film increased form $9.1 \times 10^{20}$ to $1.12 \times 10^{21} \mathrm{~cm}^{-3}$ with an increase in the film thickness from 200 to $600 \mathrm{~nm}$; therefore, the $\omega_{p}$ value shift to high energy when the increase in ITO thickness, as shown in Figure 6b. Despite the good IRB-shielding properties, the cost of indium becomes too prohibitive due to the scarcity of indium. To address the indiumscarcity issues, significant effort has been devoted for development of ITO-alternative materials with high infrared shielding properties, such as gallium-doped $\mathrm{ZnO}$ films [25], conductive metal oxides (CMO) plasmonic nanostructures [40], CMO nanocrystals [41], and degenerately doped semiconductor nanocrystals [42].

\section{3. $\mathrm{TiO}_{2} / \mathrm{SiO}_{2}$ IRA-Shielding Multilayers}

The IRB radiation is almost completely absorbed by an ITO film at the thickness of $>400 \mathrm{~nm}$. However, as the IR radiation absorption edge of the ITO film is limited to $\sim 1300 \mathrm{~nm}$, the IRA light is not completely shielded by a single ITO layer because of its limited free carrier density. Therefore, to develop a coating with optimal IRAshielding abilities, a series of $\mathrm{TiO}_{2} / \mathrm{SiO}_{2}$ multilayer films with different stacking structure was designed. NIR-reflecting multilayer coatings composed of the high-refractive-index $\mathrm{TiO}_{2}$ and low-refractive-index $\mathrm{SiO}_{2}$ films were deposited on glass substrates using the shielded CAPE and RF sputtering deposition processes, respectively. As the IRA waves undergo constructive interference, the thickness of a $\mathrm{TiO}_{2} / \mathrm{SiO}_{2}$ alternating multilayer is set to be equal to the quarter of the IRA wavelength [43]. The thickness $(t)$ values of the individual $\mathrm{TiO}_{2}$ and $\mathrm{SiO}_{2}$ films determined using the relationship $t=\lambda_{B} / 4 n$ [43], where $\mathrm{n}$ is the refractive index $\left(\mathrm{TiO}_{2}: 2.25, \mathrm{SiO}_{2}: 1.45\right)$ and $\lambda_{B}$ is the Bragg wavelength. $\mathrm{TiO}_{2}\left(\mathrm{SiO}_{2} / \mathrm{TiO}_{2}\right)_{x}$ stacked multilayers with $\mathrm{TiO}_{2} / \mathrm{SiO}_{2}$ pairs $(x)$ equal to $1-3$ are designed to fulfill a Bragg wavelength $\left(\lambda_{B}\right)$ of $\sim 950 \mathrm{~nm}$. According to a quarter of the Bragg wavelength relationship $\left(t=\lambda_{B} / 4 n\right)$, the thickness of each oxide layer was 163.8 and $105.6 \mathrm{~nm}$ for $\mathrm{SiO}_{2}$ and $\mathrm{TiO}_{2}$, respectively. 
Figure 7 shows the transmittance spectra of the coatings with various structures that fulfill a Bragg wavelength of $950 \mathrm{~nm}$, viz., (I) $\mathrm{TiO}_{2}\left(\mathrm{SiO}_{2} / \mathrm{TiO}_{2}\right)$, (II) $\mathrm{TiO}_{2}\left(\mathrm{SiO}_{2} / \mathrm{TiO}_{2}\right)_{2}$, and (III) $\mathrm{TiO}_{2}\left(\mathrm{SiO}_{2} / \mathrm{TiO}_{2}\right)_{3}$. Table 2 lists the average $T_{\text {VIS }}, T_{\text {IRA }}$, and $T_{\text {IRB }}$ values of the $\mathrm{SiO}_{2} / \mathrm{TiO}_{2}$ multilayers, viz., structures (I), (II), and (III). The $T_{V I S}$ (i.e., the transmittance in the visible light region) decreases from 81.6 to $72.7 \%$ with an increase in the number of pairs (x) in the order of (I) $>$ (II) $>$ (III). The $T_{\text {IRA }}$ significantly decreases from 45.1 to $38.2 \%$ with an increase in the number of $\mathrm{TiO}_{2} / \mathrm{SiO}_{2}$ pairs from 1 to 3 , which attributes to the increase in the number of reflections, and the constructive interference of the multiply reflected waves originating from the structure with an increased number of $\mathrm{TiO}_{2} / \mathrm{SiO}_{2}$ pairs [43]. The $\mathrm{TiO}_{2} / \mathrm{SiO}_{2}$ multilayer shielded the IRA light; however, the transmittance spectra of the optical structures denoted as (I), (II), and (III) indicated high transmittances $\left(>88.8 \%\right.$ ) in the IRB region (as shown in Table 2). The band width of a $\mathrm{TiO}_{2} / \mathrm{SiO}_{2}$ multilayer depends on the difference in the refractive index of its constituent materials; a greater difference results in a greater IRA-shielding band width, while an increase in the number of pairs may narrow the band width. The $\mathrm{TiO}_{2}\left(\mathrm{SiO}_{2} / \mathrm{TiO}_{2}\right)_{3}$ multilayer (design III) exhibited the best IRA-shielding abilities; however, its band width was only $420 \mathrm{~nm}$ in the IRA wavelength range of 760-1200 nm, as indicated in Figure 7. Therefore, the NIR radiation was not completely shielded by the single-Bragg wavelength $\mathrm{TiO}_{2}\left(\mathrm{SiO}_{2} / \mathrm{TiO}_{2}\right)_{x}$ multilayer owing to the constrained difference between the refractive indices of the constituent layers.

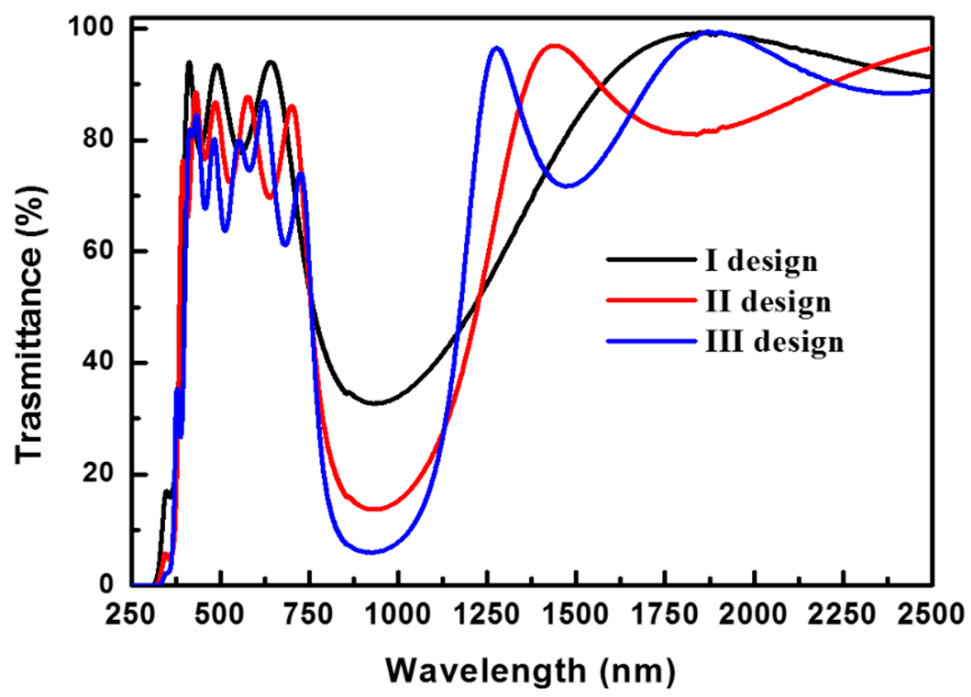

Figure 7. Transmittance spectra corresponding to various optical designs, viz., (I) $\mathrm{TiO}_{2}\left(\mathrm{SiO}_{2} / \mathrm{TiO}_{2}\right)$, (II) $\mathrm{TiO}_{2}\left(\mathrm{SiO}_{2} / \mathrm{TiO}_{2}\right)_{2}$, and (III) $\mathrm{TiO}_{2}\left(\mathrm{SiO}_{2} / \mathrm{TiO}_{2}\right)_{3}$ with a Bragg wavelength of $950 \mathrm{~nm}$.

To study the effects of the microstructure on the optical properties of the $\mathrm{TiO}_{2} / \mathrm{SiO}_{2}$ IRA-shielding multilayer films, representative cross-sectional specimens prepared by the FIB method for a $\mathrm{TiO}_{2} / \mathrm{SiO}_{2}$ multilayer with design (III) was analyzed by TEM. Figure 8a shows a BF TEM image of a $\mathrm{SiO}_{2} / \mathrm{TiO}_{2}$ multilayer with design (III) deposited on a glass substrate. The $\mathrm{BF}$ image clearly shows that the $\mathrm{SiO}_{2}$ and $\mathrm{TiO}_{2}$ layer are dense and uniform. The interfaces of the multilayers are sharp, indicating that the inter-diffusion of atoms across the $\mathrm{SiO}_{2} / \mathrm{TiO}_{2}$ interfaces is not significant owing to the low growth temperature. In order to identify the phase and investigate the orientation of the $\mathrm{TiO}_{2}$ grains, Figure $8 \mathrm{~b}$ shows a magnified BF TEM image for the square region marked as 1 in Figure 8a, and the corresponding selected-area diffraction pattern (SADP) of the $\mathrm{TiO}_{2}$ film is shown in the inset of Figure $8 \mathbf{b}$, as indicated for region 2 in Figure 8b. The SADP was recorded along the [111] zone axis and the SADP could be indexed to the anatase-phase $\mathrm{TiO}_{2}$ with the lattice parameters of $\mathrm{a}=0.3785 \mathrm{~nm}$ and $\mathrm{c}=0.9513 \mathrm{~nm}$ [8]. The SADP of the film deposited on amorphous $\mathrm{SiO}_{2}$ showed (101) preferred orientation, indicating that the $\mathrm{TiO}_{2}$ crystallites grow along the [101] axis. The magnified BF TEM image and SADP 
unequivocally demonstrate that a highly crystalline $\mathrm{TiO}_{2}$ film was obtained by the shielded CAPE process at a low growth temperature. Therefore, the $\mathrm{TiO}_{2}$ films with high visible-light transparency and high refractive index (2.25) were obtained.
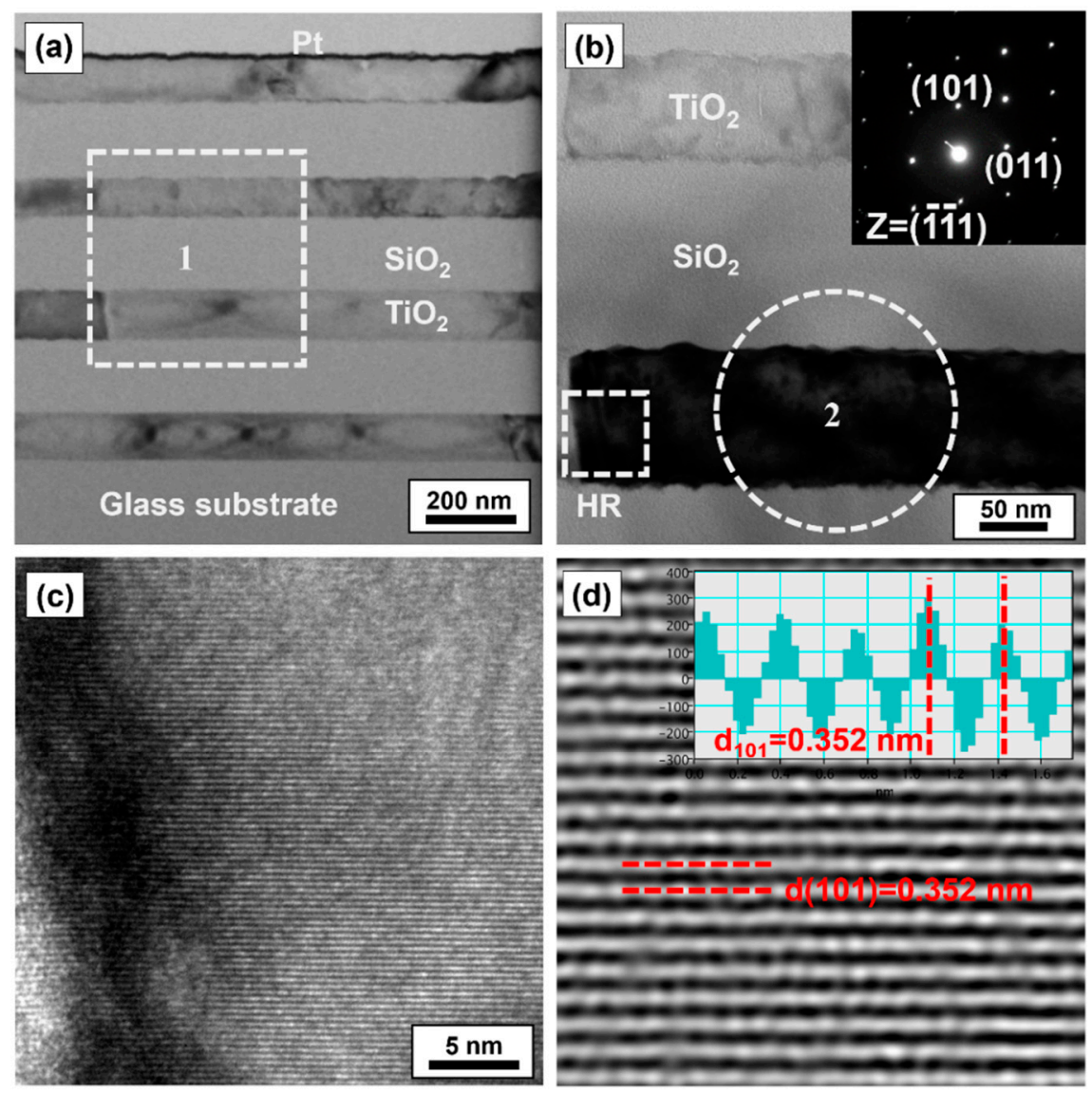

Figure 8. (a) A cross-sectional bright-field transmission electron microscopy (TEM) image of an IRA-shielding $\mathrm{TiO}_{2}\left(\mathrm{SiO}_{2} / \mathrm{TiO}_{2}\right)_{3}$ multilayer film with a Bragg wavelength of $950 \mathrm{~nm}$ deposited on a glass substrate. (b) A High-magnification TEM image of region 1 in (a). Inset shows a diffraction pattern of the anatase-phase $\mathrm{TiO}_{2}$ grains from region 2 in (b). (c) High-resolution TEM image of the HR region in (b). (d) A two-dimensional inverse fast Fourier transform image of the HR-TEM image.

In general, the deposition temperature required to form highly crystalline $\mathrm{TiO}_{2}$ films is greater than $400{ }^{\circ} \mathrm{C}$ [15]. This is attributed to the ion-assisted growth resulting from the highdensity plasma of CAPE. Previously, the kinetics of the crystallization of amorphous $\mathrm{TiO}_{2}$ to the anatase phase has been studied by differential scanning calorimetry, and the activation energy of crystallization has been determined to be $202.4 \mathrm{~kJ} / \mathrm{mol}(\sim 2.1 \mathrm{eV} /$ atom) [44]. In the arc plasma, each ion has kinetic and potential energies, which contribute to the energy delivered to adatoms on the growing film, a process referred to as atomic scale heating (ASH) [45]. The ionization energy of multiple charged ions contributes predominantly to the potential energy in the CAPE process, and the ionization energy is in the range of several electron volts to hundreds of electron volts depending on the charge state of the ion [45]; note that this ionization energy is much higher than that of the thermal evaporation or magnetron sputtering techniques [12]. The activation energies for the surface diffusion of the adatoms of $\mathrm{Ti}$ and $\mathrm{O}$ on the $\mathrm{TiO}_{2}$ surface are typically $\sim 0.5 \mathrm{eV}$ [46] and $2 \mathrm{eV} \mathrm{[47],}$ respectively. These activation energies for the surface diffusion of the adatoms on growing films are smaller than those provided by the ASH in the cathodic arc plasma; this results in enhanced surface mobility during the deposition process.

Figure $8 \mathrm{c}$ shows a high-resolution (HR) TEM image of the square region marked as HR in Figure 8c. Figure 8d shows a two-dimensional inverse fast Fourier transform (2D IFFT) 
image corresponding to Figure 8c. The 2D IFFT image indicates the planes of the anatase $\mathrm{TiO}_{2}$ (101) planes (viewed edge on) with an interplanar spacing of $0.35 \mathrm{~nm}$, suggesting that ideal (line- and planar-defect-free) $\mathrm{TiO}_{2}$ crystallites were grown in the [101] direction. Moreover, the (101) lattice plane grew perpendicular to the film growth direction, leading to a (101)-textured microstructure. As the (101) plane of $\mathrm{TiO}_{2}$ is thermodynamically stable because of its lower surface free energy than those of other planes [28], the adatoms on the (101) crystalline plane diffuse faster, resulting in the growth of grains with (101) orientation. These results are consistent with the $\mathrm{XRD}$ results of the $\mathrm{TiO}_{2}$ films.

\subsection{UV/NIR-Shielding Double-Sided Coatings}

To obtain a better UV-shielding rate and wide-range NIR-shielding ability of the coatings; thus, UV/NIR-shielding double-sided coatings were fabricated. These doublesided UV/NIR coatings consist of quarter-wave stacks of $\mathrm{SiO}_{2} / \mathrm{TiO}_{2}$ multilayers and ITO films with different thicknesses $(200-600 \mathrm{~nm})$ on different side of glass. Figure 9 shows the transmittance spectra of the different optical structures, viz., (I) $\mathrm{TiO}_{2}\left(\mathrm{SiO}_{2} / \mathrm{TiO}_{2}\right)$, (II) $\mathrm{TiO}_{2}\left(\mathrm{SiO}_{2} / \mathrm{TiO}_{2}\right)_{2}$, and (III) $\mathrm{TiO}_{2}\left(\mathrm{SiO}_{2} / \mathrm{TiO}_{2}\right)_{3}$ with different ITO film thicknesses $(0-600 \mathrm{~nm})$. Table 3 summarizes the key parameters used in the evaluation of the performance and characteristics of the different designs with various ITO film thicknesses in the range of 0 to $600 \mathrm{~nm}$. That is, the average UV transmittance in the range of UVB to UVA ( $\left.T_{U V B \sim U V A}\right)$, average visible light transmittance $\left(T_{V I S}\right)$, average IRA transmittance $\left(T_{I R A}\right)$, average IRB transmittance $\left(T_{I R B}\right.$ ), average NIR (wavelength: $760-2500 \mathrm{~nm}$ ) transmittance $\left(T_{N I R}\right), U V B$ to UVA-shielding rate $\left(S_{U V B \sim U V A}=100 \%-T_{U V B \sim U V A}\right)$, NIR-shielding rate $\left(S_{N I R}=100 \%-T_{N I R}\right)$, figure of merit $\left(S_{U V B \sim U V A} \times T_{V I S} \times S_{N I R}\right)$, and transparent thermal insulation index $(K)$ of the $\mathrm{SiO}_{2} / \mathrm{TiO}_{2}$ multilayers of designs (I), (II), and (III) are compared. In the evaluation of a coating, the UV-shielding properties in the UVB to UVA range, visible light transmittance, and NIR-shielding ability should be taken into consideration; therefore, the product of $S_{U V B} \sim U V A, T_{V I S}$, and $S_{N I R}\left(S_{U V B} \sim U V A \times T_{V I S} \times S_{N I R}\right)$ is defined as the figure of merit (FOM). A larger FOM value indicates both a better transparency in visible light and a better UV/NIR-shielding performance. The $T_{U V B} \sim U V A$ value not only decreased with increasing in the number of $\mathrm{SiO}_{2} / \mathrm{TiO}_{2}$ pairs, but also with an increase in the ITO film thickness. The enhancement of the UV-shielding properties is due to the band-to-band absorptions of the anatase $\mathrm{TiO}_{2}$ and ITO films. Therefore, the $\mathrm{TiO}_{2}\left(\mathrm{SiO}_{2} / \mathrm{TiO}_{2}\right)_{3}$ multilayer coating with different ITO film thicknesses $(0-600 \mathrm{~nm})$ exhibited $S_{U V B \sim U V A}$ values of $>90 \%$.

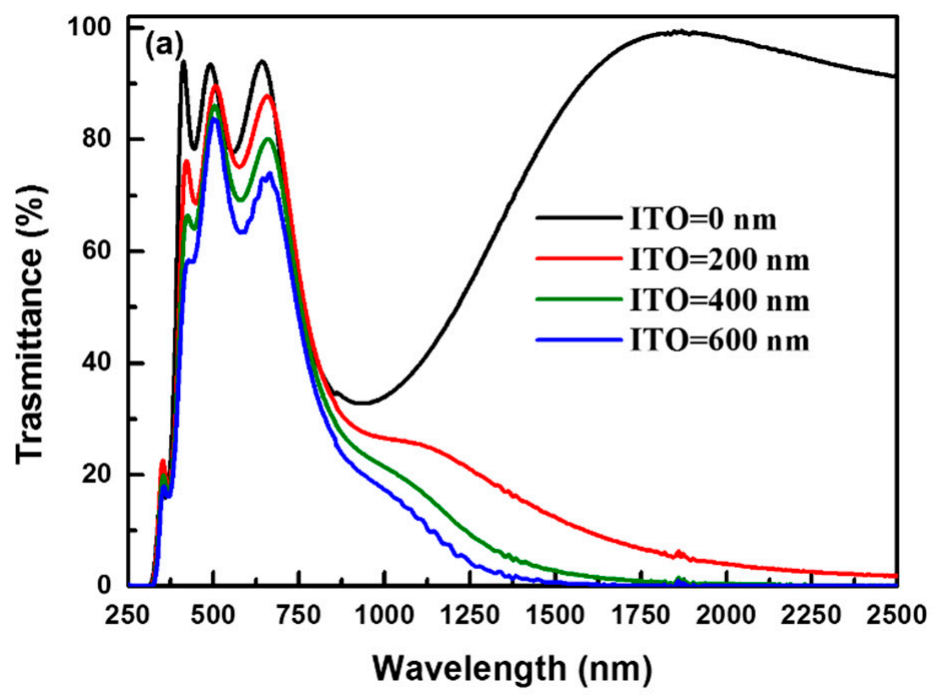

Figure 9. Cont. 

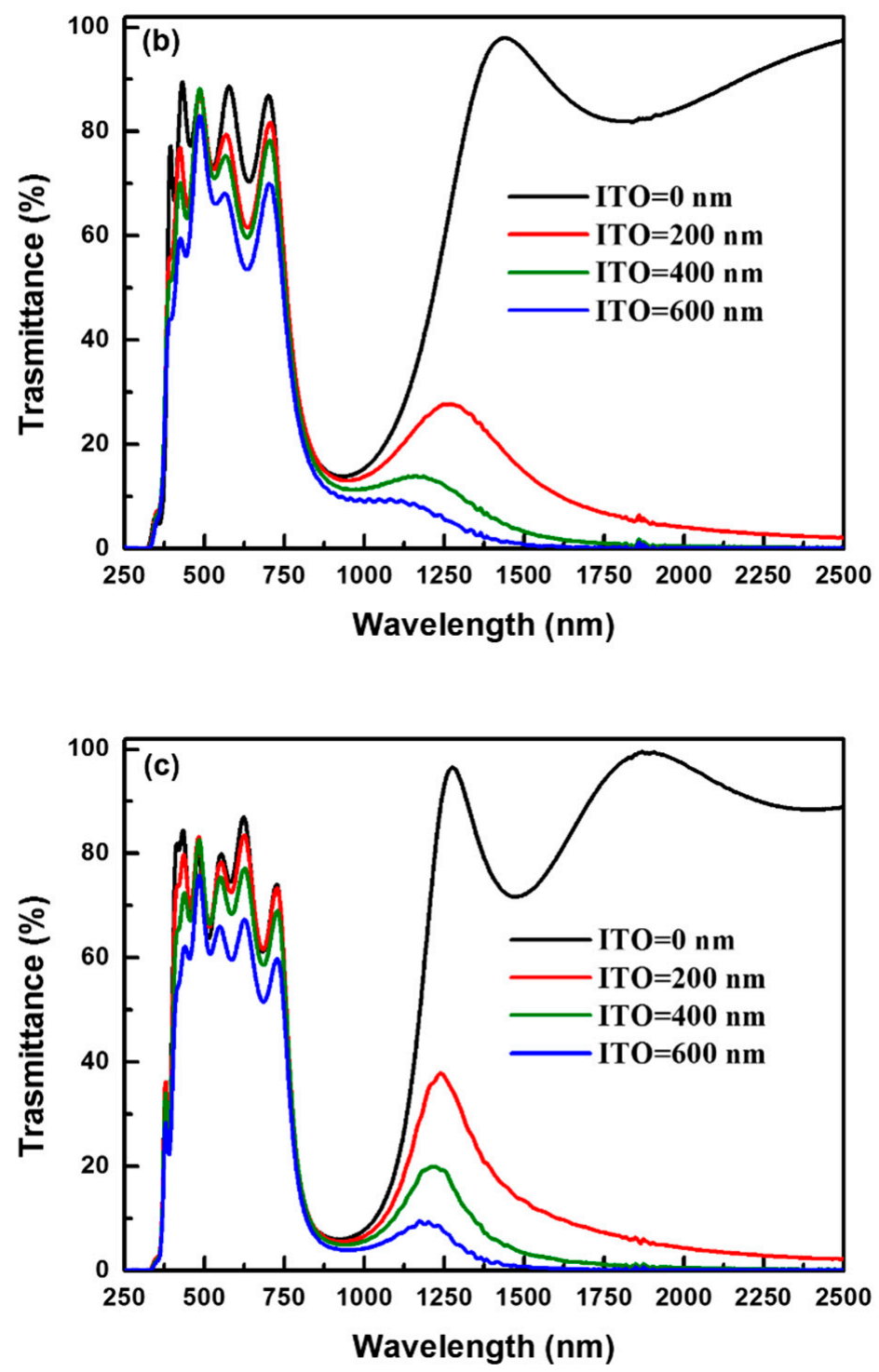

Figure 9. Transmittance spectra of various optical designs, namely (a) $\mathrm{TiO}_{2}\left(\mathrm{SiO}_{2} / \mathrm{TiO}_{2}\right)$, (b) $\mathrm{TiO}_{2}\left(\mathrm{SiO}_{2} / \mathrm{TiO}_{2}\right)_{2}$, and (c) $\mathrm{TiO}_{2}\left(\mathrm{SiO}_{2} / \mathrm{TiO}_{2}\right)_{3}$ with various ITO film thicknesses $(0 \sim 600 \mathrm{~nm})$.

The $T_{V I S}$ values of all the optical designs decreased with the increase in the ITO film thickness from 0 to $600 \mathrm{~nm}$. This decrease in the visible light absorption may be attributed to the $\mathrm{s}^{2} \rightarrow \mathrm{sp}$ bonding transition of $\mathrm{Sn}^{2+}$ [33]. The $S_{\text {NIR }}$ of the UV/NIR-shielding films increased with increasing ITO film thickness. The IRB radiation was almost completely shielded (i.e., $T_{I R B} \leq 1 \%$ ) at the ITO film thickness of $>400 \mathrm{~nm}$. This is because ITO has highdensity free carriers, resulting in plasmon resonance absorption in the IR range. Therefore, the ITO thickness should be restricted to achieve a balance between the transparency in visible light and NIR- and UV-shielding rate. All the structures with an ITO thickness of $400 \mathrm{~nm}$ showed a high NIR-shielding rate $\left(S_{\text {NIR }}>92 \%\right)$ and a high $T_{V I S}$ value $(>68 \%)$. The three types of the optical designs combined with the $400 \mathrm{~nm}$ ITO film yielded a higher FOM $\left(S_{U V B \sim U V A} \times T_{V I S} \times S_{\text {NIR }}\right)$ of $>0.58$, which indicates their better transparency and UV/NIRshielding properties over other UV/NIR-shielding coatings with ITO film thicknesses of 200 and $600 \mathrm{~nm}$. Among the metal-free double-side shielding coatings, $400 \mathrm{~nm}$ thick ITO films combined with $\mathrm{TiO}_{2}\left(\mathrm{SiO}_{2} / \mathrm{TiO}_{2}\right)_{3}$ multilayers with the optical structure of (III) yielded the highest figure of merit $(0.60)$ the corresponding average visible light transmittance is $68.1 \%$, near-infrared shielding rate is $94.8 \%$, and UVB to UVA-range shielding rate is $92.7 \%$. 
Table 3. Average UV light transmittance in the range of UVB to UVA ( $T_{U V B \sim U V A}$ ), average visible light transmittance $\left(T_{V I S}\right)$, average IRA light transmittance $\left(T_{I R A}\right)$, average IRB light transmittance $\left(T_{I R B}\right)$, average near IR light (wavelength: $760-2500 \mathrm{~nm})$ transmittance $\left(T_{N I R}\right)$, UVB to UVA shielding rate $\left(S_{U V B} \sim U V A=100 \%-T_{U V B} \sim U V A\right)$, near-IR shielding rate $\left(S_{N I R}=100 \%-T_{N I R}\right)$, figure of merit $\left(F O M=S_{U V B \sim U V A} \times T_{V I S} \times S_{N I R}\right)$ value, and transparent thermal insulation index $(K)$ of UV/NIR-shielding double-sided coatings with different optical designs and different thicknesses of the ITO film $(200-600 \mathrm{~nm})$.

\begin{tabular}{|c|c|c|c|c|c|c|c|c|c|c|}
\hline $\begin{array}{l}\text { Optical } \\
\text { Design }\end{array}$ & $\begin{array}{c}\text { ITO } \\
\text { Thickness } \\
\text { (nm) }\end{array}$ & $\underset{(\%)}{T_{U V B \sim U V A}}$ & $T_{V I S}(\%)$ & $T_{I R A}(\%)$ & $T_{I R B}(\%)$ & $T_{N I R}(\%)$ & $S_{N I R}(\%)$ & $S_{\text {UVB } U \text { UVA }}$ & FOM & K \\
\hline \multirow{4}{*}{ I } & 0 & 16.0 & 81.6 & 45.1 & 93.5 & 75.7 & 24.3 & 84.0 & 0.17 & 1.08 \\
\hline & 200 & 13.0 & 76.8 & 26.4 & 5.8 & 13.4 & 86.6 & 87.0 & 0.58 & 5.75 \\
\hline & 400 & 12.0 & 71.2 & 18.9 & 0.7 & 7.6 & 92.4 & 88.0 & 0.58 & 9.43 \\
\hline & 600 & 10.5 & 66.0 & 14.6 & 0.2 & 5.5 & 94.5 & 89.5 & 0.56 & 11.93 \\
\hline \multirow{4}{*}{ II } & 0 & 14.1 & 77.8 & 38.5 & 89.3 & 70.5 & 29.5 & 85.9 & 0.20 & 1.10 \\
\hline & 200 & 12.6 & 72.0 & 21.3 & 6.4 & 11.9 & 88.1 & 87.4 & 0.55 & 6.07 \\
\hline & 400 & 11.9 & 69.3 & 13.8 & 0.8 & 5.7 & 94.3 & 88.1 & 0.58 & 12.07 \\
\hline & 600 & 10.4 & 62.6 & 9.9 & 0.2 & 3.8 & 96.2 & 89.6 & 0.54 & 16.51 \\
\hline \multirow{4}{*}{ III } & 0 & 9.4 & 72.7 & 38.2 & 88.8 & 70.6 & 29.4 & 90.6 & 0.19 & 1.03 \\
\hline & 200 & 7.9 & 71.7 & 19.0 & 6.4 & 11.0 & 89.0 & 92.1 & 0.59 & 6.52 \\
\hline & 400 & 7.3 & 68.1 & 12.2 & 0.8 & 5.2 & 94.8 & 92.7 & 0.60 & 12.97 \\
\hline & 600 & 6.2 & 59.8 & 7.4 & 0.2 & 2.9 & 97.1 & 93.8 & 0.55 & 20.98 \\
\hline
\end{tabular}

To compare the transparent thermal insulation performance of the transparent UV/NIRshielding films with recent studies of transparent IR-sheading materials, the transparent thermal insulation index was used. The transparent thermal insulation index $(K)$ is defined as the ratio of the average visible light transmittance $\left(T_{V I S}\right)$ to the average NIR transmittance $\left(T_{N I R}\right)[48,49]$, expressed as follows:

$$
K=T_{V I S} / T_{N I R}
$$

A higher $K$ value implies better performance and the $K$ values of the different coatings in this work are listed in Table 3. In general, the typical $K$ values for $\mathrm{Cs}_{\mathrm{x}} \mathrm{WO}_{3}$-based films with excellent transparent thermal insulation performance are in the range of 7-9 [48,49]. Table 3 summarizes the $K$ values of the UV/NIR-shielding coatings prepared in this study. The $K$ values of our UV/NIR-shielding coatings not only increased with the increase in the ITO film thickness from 0 to $600 \mathrm{~nm}$, but also with an increase in the number of $\mathrm{SiO}_{2} / \mathrm{TiO}_{2}$ pairs. The high-performance transparent thermal insulation coatings of different optical structures with a $K$ value of $>9.43$ could be obtained using an ITO film thickness of $>400 \mathrm{~nm}$. Among the prepared oxide-based shielding coatings, $600 \mathrm{~nm}$ thick ITO films combined with the $\mathrm{TiO}_{2}\left(\mathrm{SiO}_{2} / \mathrm{TiO}_{2}\right)_{3}$ multilayers (optical design (III)) yielded the highest $K$ value (20.98), which is better than those of the Pt-doped $\mathrm{Cs}_{\mathrm{x}} \mathrm{WO}_{3}$ nanorods $(K=8.79)$ [48] and two-dimensional nano- $\mathrm{Cs}_{x} \mathrm{WO}_{3}$ films $(K=7.1)$ [49]. According to the $K$ value analysis, it can be concluded that the UV/NIR-shielding coatings developed in this study have excellent thermal insulation performance, and can be prepared at a low deposition temperature of $<150{ }^{\circ} \mathrm{C}$. The excellent transparent thermal insulation performance of the UV/NIR-shielding coatings along with high visible transparency and NIR-shielding performance renders them suitable to be applied as energy-saving window coatings in buildings and automobiles.

\subsection{Effects of UVB/IR Radiations on Human Skin Cells (Human Dermal Fibroblasts)}

Photoaging is the most crucial factor on causing skin aging damage. The light-induced ROS generation elicits inflammatory cytokines releasing, DNA modification and oxidative damage. Previous study has revealed that UVB-induced skin is damaged by the excess of ROS generation in human dermal fibroblasts [50]. NIR radiation induced cellular 
senescence in human keratinocyte, which resulted in premature skin aging [51]. Moreover, the IR radiation reduces the amount of the endogenous antioxidant enzyme catalase and superoxide dismutase, leading to the deterioration of the antioxidant defense capability against oxidative stress [52]. The effect of the UVB or IR or UVB/IR radiation on the ROS generation was therefore examined. Human dermal fibroblast cell line CCD-966SK cells were exposed to UVB or IR or UVB/IR, and intracellular ROS levels were determined DCF fluorescence using flow cytometry. As shown in Figure 10a, a 2.48-fold increase in the ROS generation was noted when the human dermal fibroblasts were exposed to UVB radiation. No significant change in the ROS generation was observed with IR-irradiated cells. The mean intensity following the $\mathrm{H}_{2}$ DCFDA staining was significantly higher in the UVB/IR-irradiated cells than in the UVB-irradiated cells, consistent with increased ROS generation in the UVB/IR-irradiated cells (4.22-fold increase), suggesting that the increased production of ROS in the UVB/IR-exposed human fibroblasts is related to the IR irradiation-induced decrease in the antioxidant defense capability of the skin. Previous studies have revealed that increased oxidative stress in the skin leads to inflammatory responses, which involve the production of various inflammatory cytokines such as TNF- $\alpha$ and IL-6 [53]. Real-time PCR analyses revealed that the amounts of TNF- $\alpha$ mRNA and IL-6 mRNA expressed in the UVB/IR-irradiated cells are higher than that in the UVB- or IR-irradiated cells (Figure 10b), suggesting that the oxidative stress causes the increase in the expression of the inflammatory cytokines, TNF- $\alpha$ and IL-6.

(a)

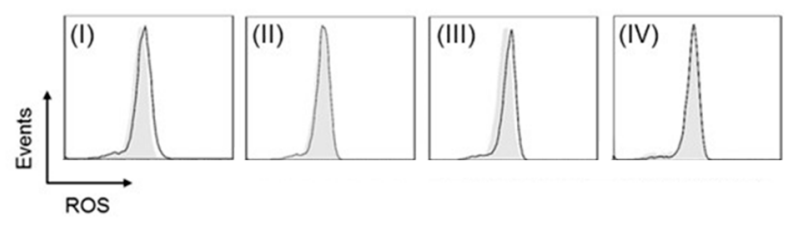

(b)

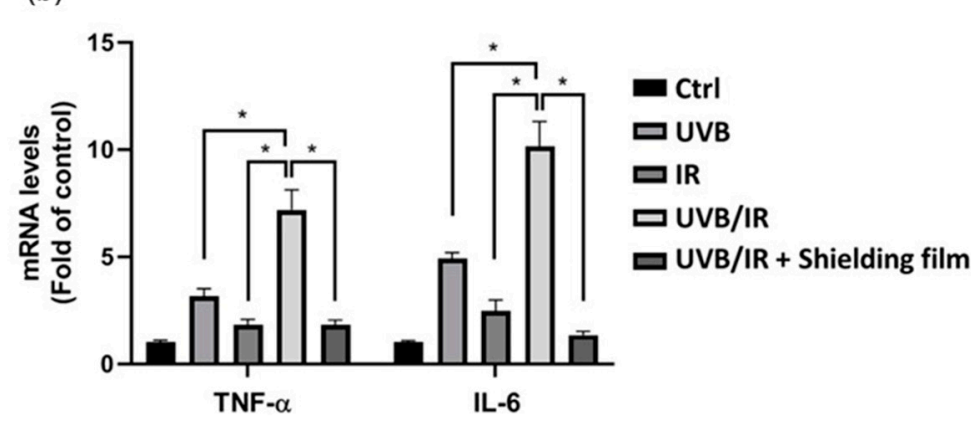

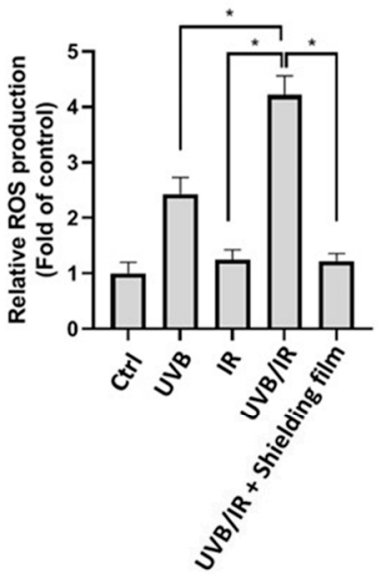

Figure 10. Effect of UVB/IR radiation on human dermal fibroblasts. (a) Effect of the UVB/IR radiation with or without the use of a shielding film on the ROS generation of CCD-966SK. The cells were irradiated with $10 \mathrm{~mJ} / \mathrm{cm}^{2}$ UVB light, $140 \mathrm{~J} / \mathrm{cm}^{2}$ IR light, or UVB/IR without/with the use of a shielding film. (Left panel) A flow cytometry histograms of DCFDA staining in controls (gray filled histograms) and treatments (black line histograms). (Right panel) Relative fluorescence intensities from flow cytometry $\left(\mathrm{n}=3\right.$, mean $\left.\pm \mathrm{SD},{ }^{*} p<0.05\right)$. (I) With UVB irradiation, (II) with IR irradiation, (III) with UVB/IR irradiation, (IV) with UVB/IR irradiation through the shielding film. (b) Effect of the UV/IR irradiation with or without the use of shielding film on the TNF- $\alpha$ and IL- 6 mRNA levels. The mRNA levels were analyzed by real-time PCR $(n=3$, mean $\pm S D, * p<0.05)$.

The metal-free UV/NIR-shielding coatings were also evaluated for their ability to protect human skin cells from UVB/IR through ROS generation and inflammatory cytokine (TNF- $\alpha$ and IL-6) mRNA up-regulation in human dermal fibroblasts. We selected the structure with the highest figure of merit and $\mathrm{K}$ value, $\mathrm{TiO}_{2}\left(\mathrm{SiO}_{2} / \mathrm{TiO}_{2}\right)_{3}$ multilayers 
combined with the $600 \mathrm{~nm}$ ITO film, to study the influence of the UVB/IR-shielding coating on the dermal fibroblasts. As shown in Figure 10a, the ROS generation of the fibroblasts protected by the UV/NIR-shielding film was lower than that of the unshielded UVB/IRexposed fibroblasts. This result suggested that the UV/NIR-shielding film significantly decreased the UV/IR transmittance, thereby decreasing the deleterious effects of the UVB/IR radiation through ROS generation. Moreover, these cells displayed TNF- $\alpha$ and IL-6 mRNA up-regulation after a $24 \mathrm{~h}$ exposure to UV/IR irradiation. However, when protected with the UV and NIR-shielding film, they exhibited reduced expression of the UVB/IR-induced inflammatory cytokines (Figure 10b). These data demonstrate that the metal-free UV/NIR-shielding coatings effectively suppressed the UVB/IR-induced ROS generation and inflammatory responses in a human dermal fibroblast cell line. Thus, this work provides practical applications of metal-free high-performance UV/NIR-shielding coatings for human skin protection.

\section{Conclusions}

We employed a novel method to fabricate a metal-free UV/NIR-shielding coating with high IR- and UV-shielding performance and high transmittance in visible light for energy-saving applications and human skin protection. These double-sided coatings consist of quarter-wave stacks of $\mathrm{SiO}_{2} / \mathrm{TiO}_{2}$ multilayers and ITO films on different side of glass, which were responsible for blocking the IRA and IRB radiations, respectively. The total thicknesses of UV/near infrared-shielding films are in the range from $375 \mathrm{~nm}$ to $1513.8 \mathrm{~nm}$. The high-performance UV-shielding properties are due to the band-toband absorptions of the anatase $\mathrm{TiO}_{2}$ and ITO films. TEM analysis revealed that the $\mathrm{SiO}_{2} / \mathrm{TiO}_{2}$ multilayers had a uniform and dense structure. A highly crystalline $\mathrm{TiO}_{2}$ film with a (101) preferred orientation was obtained by the shielded CAPE process at a low growth temperature of $100^{\circ} \mathrm{C}$. The ITO films were highly crystalline and their free electron concentration increased from $9.2 \times 10^{20}$ to $1.12 \times 10^{21} \mathrm{~cm}^{-3}$ with increasing thickness, leading to strong absorption of IRB due to the plasmon resonance absorption. Among the metal-free shielding coatings studied, coatings with a $400 \mathrm{~nm}$ thick ITO film combined with $\mathrm{TiO}_{2}\left(\mathrm{SiO}_{2} / \mathrm{TiO}_{2}\right)_{3}$ multilayers (optical design (III)) yielded the highest figure of merit (0.60); the corresponding average transmittance in visible light is $68.1 \%$, and the NIR shielding rate is $96 \%$ and UVB to UVA range shielding rate is $92.7 \%$. According to the transparent thermal insulation index evaluation, $600 \mathrm{~nm}$ thick ITO films combined with the $\mathrm{TiO}_{2}\left(\mathrm{SiO}_{2} / \mathrm{TiO}_{2}\right)_{3}$ multilayers (optical design (III)) has the highest $\mathrm{K}$ value (20.98). The effects of the UV/NIR radiation on human skin cells indicated a significantly reduced ROS generation and inflammatory cytokine expression of the skin cells protected by a UV/NIR-shielding coating as compared to those of the unprotected specimens.

Author Contributions: Conceptualization, C.-H.L. and Y.-J.C.; methodology, C.-H.L. and Y.-J.C.; validation, C.-H.L. and Y.-J.C.; formal analysis, C.-H.L. and Y.-J.C.; investigation, C.-H.L. and Y.-J.C.; data curation, C.-H.L. and Y.-J.C.; writing-original draft preparation, C.-H.L.; writing-review and editing, Y.-J.C. Both authors have read and agreed to the published version of the manuscript.

Funding: This research was funded by the Ministry of Science and Technology Of FUNDER grant number MOST-109-2320-B-037-008.

Acknowledgments: This work was supported by the Ministry of Science and Technology, Taiwan, ROC (MOST-109-2320-B-037-008).

Conflicts of Interest: The authors declare no conflict of interest.

\section{References}

1. Farage, M.A.; Miller, K.W.; Elsner, P.; Maibach, H.I. Structural characteristics of the aging skin: A review. Cutan. Ocul. Toxicol. 2007, 26, 343-357. [CrossRef]

2. Scalia, S.; Molinari, A.; Casolari, A.; Maldotti, A. Complexation of the sunscreen agent, phenylbenzimidazole sulphonic acid with cyclodextrins: Effect on stability and photo-induced free radical formation. Eur. J. Pharm. Sci. 2004, 22, 241-249. [CrossRef] [PubMed] 
3. Roewert-Huber, J.; Lange-Asschenfeldt, B.; Stockfleth, E.; Kerl, H. Epidemiology and aetiology of basal cell carcinoma. Br. J. Dermatol. 2007, 157, 45-57. [CrossRef]

4. Stockfleth, E.; Ulrich, C.; Leverkus, M.; Eberle, J. UV-induced squamous cell carcinoma-A role for antiapoptotic signalling pathways. Br. J. Dermatol. 2009, 161, 107-115.

5. Abundiz-Cisneros, N.; Sanginés, R.; Rodríguez-López, R.; Peralta-Arriola, M.; Cruz, J.; Machorro, R. Novel Low-E filter for architectural glass panel. Energy Build. 2020, 206, 109558. [CrossRef]

6. Barolet, D.; Christiaens, F.; Hamblin, M.R. Infrared and skin: Friend or foe. J. Photochem. Photobiol. B Biol. 2016, 155, 78-85. [CrossRef] [PubMed]

7. Schroeder, P.; Haendeler, J.; Krutmann, J. The role of near infrared radiation in photoaging of the skin. Exp. Gerontol. 2008, 43, 629-632. [CrossRef]

8. Wang, C.L.; Hwang, W.S.; Chu, H.L.; Lin, H.J.; Ko, H.H.; Wang, M.C. Kinetics of anatase transition to rutile $\mathrm{TiO}_{2}$ from titanium dioxide precursor powders synthesized by a sol-gel process. Ceram. Int. 2016, 42, 13136-13143. [CrossRef]

9. Miao, L.; Jin, P.; Kaneko, K.; Terai, A.; Nabatova-Gabain, N.; Tanemura, S. Preparation and characterization of polycrystalline anatase and rutile $\mathrm{TiO}_{2}$ thin films by rf magnetron sputtering. Appl. Surf. Sci. 2003, 212, 255-263. [CrossRef]

10. Kleiman, A.; Meichtry, J.M.; Vega, D.; Litter, M.I.; Márquez, A. Photocatalytic activity of $\mathrm{TiO}_{2}$ films prepared by cathodic arc deposition: Dependence on thickness and reuse of the photocatalysts. Surf. Coat. Technol. 2020, 382, 125154. [CrossRef]

11. Masood, M.T.; Qudsia, S.; Hadadian, M.; Weinberger, C.; Nyman, M.; Ahläng, C.; Dahlström, S.; Liu, M.; Vivo, P.; Österbacka, R.; et al. Investigation of well-defined pinholes in $\mathrm{TiO}_{2}$ electron selective layers used in planar heterojunction perovskite solar cells. Nanomaterials 2020, 10, 181. [CrossRef] [PubMed]

12. Tay, B.K.; Zhao, Z.W.; Chua, D.H.C. Review of metal oxide films deposited by filtered cathodic vacuum arc technique. Mater. Sci. $R$ Rep. 2006, 52, 1-48. [CrossRef]

13. Ohtani, B.; Ogawa, Y.; Nishimoto, S.I. Photocatalytic Activity of AmorphousAnatase Mixture of Titanium(IV) Oxide Particles Suspended in Aqueous Solutions. J. Phys. Chem. B 1997, 101, 3746-3752. [CrossRef]

14. Zhang, F.; Wang, X.; Li, C.; Wang, H.; Chen, L.; Liu, X. Rutile-type titanium oxide films synthesized by filtered arc deposition. Surf. Coat. Technol. 1998, 110, 136-139. [CrossRef]

15. Safeen, K.; Micheli, V.; Bartali, R.; Gottardi, G.; Laidani, N. Low temperature growth study of nano-crystalline TiO 2 thin films deposited by RF sputtering. J. Phys. D Appl. 2015, 48, 295201. [CrossRef]

16. Zhao, B.; Zhou, J.; Chen, Y.; Peng, Y. Effect of annealing temperature on the structure and optical properties of sputtered $\mathrm{TiO}_{2}$ films. J. Alloy. Compd. 2011, 509, 4060-4064. [CrossRef]

17. Zhao, P.; Kim, S.; Yoon, S.; Song, P. Characteristics of indium zinc oxide/silver/indium zinc oxide multilayer thin films prepared by magnetron sputtering as flexible transparent film heaters. Thin Solid Films 2018, 665, 137-142. [CrossRef]

18. Loka, C.; Park, K.R.; Lee, K.S. Multi-functional $\mathrm{TiO}_{2} / \mathrm{Si} / \mathrm{Ag}(\mathrm{Cr}) / \mathrm{TiN}_{x}$ coatings for low-emissivity and hydrophilic applications. Appl. Surf. Sci. 2016, 363, 439-444. [CrossRef]

19. Huang, J.; Xiang, C.; Li, S.; Zhao, X.; He, G. Preparation, characterization and performance of $\operatorname{Ti}_{1 x} \mathrm{Al}_{x} \mathrm{~N} / \mathrm{Ag} / \mathrm{Ti}_{1 x} \mathrm{Al}_{x} \mathrm{~N}$ lowemissivity films. Appl. Surf. Sci. 2014, 293, 259-264. [CrossRef]

20. Sahm, H.; Charton, C.; Thielsch, R. Oxidation behaviour of thin silver films deposited on plastic web characterized by spectroscopic ellipsometry (SE). Thin Solid Films 2004, 455, 819-823. [CrossRef]

21. Ando, E.; Miyazaki, M. Durability of doped zinc oxide/silver/doped zinc oxide low emissivity coatings in humid environment. Thin Solid Films 2008, 516, 4574-4577. [CrossRef]

22. Tsai, D.C.; Chang, Z.C.; Kuo, B.H.; Chen, E.C.; Huang, Y.L.; Hsieh, T.J.; Shieu, F.S. Thermal stability and optical properties of low emissivity multilayer coatings for energy-saving applications. Ceram. Int. 2020, 46, 7991-7997. [CrossRef]

23. Stamate, E. Spatially resolved optoelectronic properties of Al-Doped zinc oxide thin films deposited by radio-frequency magnetron plasma sputtering without substrate heating. Nanomaterials 2020, 10, 14. [CrossRef]

24. Liang, C.H.; Hwang, W.S. Stability of the electro-optical properties and structural characteristics of $\mathrm{H}$ and $\mathrm{Al}$ co-doped $\mathrm{ZnO}$ films after heat treatment in H/Ar plasma. Ceram. Int. 2014, 40, 11857-11868. [CrossRef]

25. Liang, C.H.; Wang, W.L.; Hwang, W.S. High-rate and low-temperature growth of ZnO: Ga thin films by steered cathodic arc plasma evaporation. Appl. Surf. Sci. 2013, 265, 621-629. [CrossRef]

26. Tan, W.K.; Yokoi, A.; Kawamura, G.; Matsuda, A.; Muto, H. PMMA-ITO composite formation via electrostatic assembly method for infra-red filtering. Nanomaterials 2019, 9, 886. [CrossRef] [PubMed]

27. Liang, C.H.; Chen, S.C.; Qi, X.; Chen, C.; Yang, C.C. Influence of film thickness on the texture, morphology and electro-optical properties of indium tin oxide films. Thin Solid Films 2010, 519, 345-350. [CrossRef]

28. Yang, X.; Zhang, M.J.; Min, Y.; Xu, M.; Mei, Z.; Liang, J.; Hu, J.; Yuan, S.; Xiao, S.; Duan, Y.; et al. Controllable Formation of (004)-Orientated $\mathrm{Nb}: \mathrm{TiO}_{2}$ for High-Performance Transparent Conductive Oxide Thin Films with Tunable Near-Infrared Transmittance. ACS Appl. Mater. Interfaces 2017, 9, 29021-29029. [CrossRef]

29. Sanders, D.M.; Anders, A. Review of cathodic arc deposition technology at the start of the new millennium. Surf. Coat. Technol. 2000, 133, 78-90. [CrossRef]

30. Liang, C.H.; Hwang, W.S.; Wang, W.L. Department Effects of growth temperature and target material on the growthbehavior and electro-optical properties of ZnO:Al films deposited by high-rate steered cathodic arc plasma evaporation. Appl. Surf. Sci. 2015, 333, 1-12. [CrossRef] 
31. Messemeche, R.; Saidi, H.; Attaf, A.; Benkhetta, Y.; Chala, S.; Azizi, R.; Nouadji, R. Elaboration and characterization of nanocrystalline layers of transparent titanium dioxide (Anatase- $\left.\mathrm{TiO}_{2}\right)$ deposited by a sol-gel (spin coating) process. Surf. Interfaces 2020, 19, 100482. [CrossRef]

32. Tahar, R.B.H.; Ban, T.; Ohya, Y.; Takahashi, Y. Tin doped indium oxide thin films: Electrical properties. J. Appl. Phys. 1998, 83, 2631. [CrossRef]

33. Liang, C.H.; Qi, X. Indium-tin-oxide thin films deposited on polyethylene-terephthalate substrates by substrate-biased RF magnetron sputtering. Surf. Coat. Technol. 2013, 231, 205-208. [CrossRef]

34. Choi, C.G.; No, K.; Lee, W.J.; Kim, H.G.; Jung, S.O.; Leeb, W.J.; Kim, W.S.; Kim, S.J.; Yoon, C. Effects of oxygen partial pressure on the microstructure and electrical properties of indium tin oxide film prepared by d.c. magnetron sputtering. Thin Solid Films 1995, 258, 274-278. [CrossRef]

35. Li, T.Q.; Noda, S.; Tsuji, Y.; Ohsawa, T.; Komiyama, H. Initial growth and texture formation during reactive magnetron sputtering of TiN on Si(111). J. Vac. Sci. Technol. A 2002, 20, 583. [CrossRef]

36. Perrotta, A.; Pilz, J.; Milella, A.; Coclite, A.M. Opto-chemical control through thermal treatment of plasma enhanced atomic layer deposited ZnO: An in situ study. Appl. Surf. Sci. 2019, 483, 10-18. [CrossRef]

37. Devi, L.G.; Kumar, S.G. Exploring the critical dependence of adsorption of various dyes on the degradation rate using $\mathrm{Ln}^{3+}-\mathrm{TiO}_{2}$ surface under UV/solar light. Appl. Surf. Sci. 2012, 261, 137-146. [CrossRef]

38. Moss, T.S. Optical Properties of Semiconductors; Butter-Worths: London, UK, 1959.

39. Solé, J.; Bausa, L.; Jaque, D. An Introduction to the Optical Spectroscopy of Inorganic Solids; John Wiley \& Sons. Ltd.: Chichester, UK, 2005.

40. Clavero, C. Plasmon-induced hot-electron generation at nanoparticle/metal-oxide interfaces for photovoltaic and photocatalytic devices. Nat. Photonics 2014, 8, 95-103. [CrossRef]

41. Agrawal, A.; Johns, R.W.; Milliron, D.J. Control of localized surface plasmon resonances in metal oxide nanocrystals. Annu. Rev. Mater. Res. 2017, 47, 1-31. [CrossRef]

42. Kriegel, I.; Scotognella, F.; Manna, L. Plasmonic doped semiconductor nanocrystals: Properties, fabrication, applications and perspectives. Phys. Rep. 2017, 674, 1-52. [CrossRef]

43. Schubert, E.F. Light-Emitting Diodes, 2nd ed.; Cambridge University Press: New York, NY, USA, 2006.

44. Mansour, S.A. Non-isothermal crystallization kinetics of nano-sized amorphous $\mathrm{TiO}_{2}$ prepared by facile sonochemical hydrolysis route. Ceram. Int. 2019, 45, 2893-2898. [CrossRef]

45. Anders, A. Atomic scale heating in cathodic arc plasma deposition. Appl. Phys. Lett. 2002, 80, 1100-1102. [CrossRef]

46. Gaberle, J.; Shluge, A. The role of surface reduction in the formation of Ti interstitial. RSC Adv. 2019, 9, 12182-12188. [CrossRef]

47. Lei, Y.; Niu, F.; Mei, H.; Liu, Q.; Pan, C.; Xiao, W. Adsorption and diffusion studies of an $\mathrm{O}$ adatom on $\mathrm{TiO}_{2}$ anatase surfaces with first principles calculations. Comput. Mater. Sci. 2012, 63, 58-65. [CrossRef]

48. Liu, J.; Ran, S.; Fan, C.; Qiao, Y.; Shi, F.; Yang, J.; Chen, B.; Liu, S. One pot synthesis of Pt-doped $\mathrm{Cs}_{x} \mathrm{WO}_{3}$ with improved near infrared shielding for energy-saving film applications. Sol. Energy 2019, 178, 17-24. [CrossRef]

49. Liu, G.; Kong, F.; Xu, J.; Li, R. Novel synthesis of $0 \mathrm{D}, 1 \mathrm{D}$ and $2 \mathrm{D}$ nano-Cs $\mathrm{WO}_{3}$ and their tunable optical-thermal response performance. J. Mater. Chem. C 2020, 8, 10342-10351. [CrossRef]

50. Wang, L.; Kim, H.S.; Oh, Y.J.; Je, J.G.; Jeon, Y.J.; Ryu, B. Protective effect of diphlorethohydroxycarmalol isolated from Ishige okamurae against UVB-induced damage in vitro in human dermal fibroblasts and in vivo in zebrafish. Food Chem. Toxicol. 2020, 136, 110963. [CrossRef]

51. Liang, C.H.; Chen, Y.J. Fabrication of oxide-based near infrared-shielding coatings for a smart window to prevent infrared-induced photoaging in human skin. Ceram. Int. 2021, 47, 5177-5186. [CrossRef]

52. Costa, A.; Eberlin, S.; Clerici, S.P.; Abdalla, B.M.Z. In vitro effects of infrared A radiation on the synthesis of MMP-1, catalase, superoxide dismutase and GADD45 alpha protein. Inflamm. Allergy Drug Targets (Former. Curr. Drug Targets Inflamm. Allergy) 2015, 14, 53-59. [CrossRef] [PubMed]

53. Karthikeyan, R.; Kanimozhi, G.; Prasad, N.R.; Agilan, B.; Ganesan, M.; Mohana, S.; Srithar, G. 7-Hydroxycoumarin prevents UVB-induced activation of NF- $\kappa$ B and subsequent overexpression of matrix metalloproteinases and inflammatory markers in human dermal fibroblast cells. J. Photochem. Photobiol. B Biol. 2016, 161, 170-176. [CrossRef] 